\title{
GCU
}

Glasgow Caledonian

University

University for the Common Good

\section{Testing superabsorbent polymer (SAP) sorption properties prior to implementation in concrete: results of a RILEM Round-Robin Test}

Mechtcherine, Viktor; Schnoeck, Didier; Schröfl, Christof; de Belie, Nele; Klemm, Agnieszka J.; Ichimiya, Kazuo; Moon, Juhyuk; Wyrzykowski, Mateusz; Lura, Pietro; Toropovs, Nikolajs; Assmann, Alexander; Igarashi, Shin-ichi; Varga, Igor De La; Almeida, Fernando C.R.; Erk, Kendra; Ribeiro, António Bettencourt; Custódio, João; Reinhardt, Hans Wolf; Falikman, Vyatcheslav

Published in:

Materials and Structures

DOI:

$10.1617 / \mathrm{s} 11527-018-1149-4$

Publication date:

2018

Document Version

Author accepted manuscript

Link to publication in ResearchOnline

Citation for published version (Harvard):

Mechtcherine, V, Schnoeck, D, Schröfl, C, de Belie, N, Klemm, AJ, Ichimiya, K, Moon, J, Wyrzykowski, M, Lura, P, Toropovs, N, Assmann, A, Igarashi, S, Varga, IDL, Almeida, FCR, Erk, K, Ribeiro, AB, Custódio, J, Reinhardt, HW \& Falikman, V 2018, 'Testing superabsorbent polymer (SAP) sorption properties prior to implementation in concrete: results of a RILEM Round-Robin Test', Materials and Structures, vol. 51, 28.

https://doi.org/10.1617/s11527-018-1149-4

\section{General rights}

Copyright and moral rights for the publications made accessible in the public portal are retained by the authors and/or other copyright owners and it is a condition of accessing publications that users recognise and abide by the legal requirements associated with these rights.

Take down policy

If you believe that this document breaches copyright please view our takedown policy at https://edshare.gcu.ac.uk/id/eprint/5179 for details of how to contact us. 
Testing SAP characteristics prior to implementation in concrete: results of a RILEM round-robin test

Viktor Mechtcherine ${ }^{\mathrm{a}}$, Didier Snoeck ${ }^{\mathrm{b}}$, Christof Schröfl ${ }^{\mathrm{a}}$, Nele De Belie ${ }^{\mathrm{b}}$, Agnieszka J. Klemm $^{c}$, Kazuo Ichimiya ${ }^{d}$, Juhyuk Moon ${ }^{e}$, Mateusz Wyrzykowski ${ }^{\dagger}$, Pietro Lura ${ }^{\dagger}$, Nikolajs Toropovs $^{f}$, Alexander Assmann ${ }^{\text {, }}$, Shin-ichi Igarashi ${ }^{\text {h }}$, Igor De La Varga', Fernando C.R. Almeida $^{c}$, Kendra Erk', António Bettencourt Ribeirok ${ }^{k}$ João Custódio ${ }^{k}$, Hans Wolf Reinhardt',

\section{Abstract}

This article presents the results of a round-robin test performed by 13 international research groups in the framework of the activities of the RILEM Technical Committee 260 RSC "Recommendations for use of superabsorbent polymers in concrete construction". Two commercially available superabsorbent polymers (SAP) with different chemical compositions and gradings were tested in terms of their kinetics of absorption in different media; demineralized water, cement filtrate solution with particular cement distributed to every participant and local cement chosen by the participant. Two absorption test methods were 
considered; the tea-bag method and the filtration method. The absorption capacity was evaluated as a function of time. The results showed correspondence in behaviour of the SAPs among all participants, but also between the two test methods, even though high scatter was observed at early minutes of testing after immersion. The tea-bag method proved to be more practical in terms of time dependent study, whereby the filtration method showed less variation in the absorption capacity after 24 hours. However, absorption followed by intrinsic, ion-mediated desorption of a respective SAP sample in the course of time was not found by the filtration method. This SAP-specific characteristic was only displayed by the teabag method. This demonstrates the practical applicability of both test methods, each one having their own strengths and weaknesses at distinct testing times.

\section{Keywords}

Absorption capacity, filtration method, kinetics, round-robin test, superabsorbent polymer, tea-bag method

The study reported in this paper was performed within the framework of the RILEM TC 260RSC "Recommendations for Use of Superabsorbent Polymers in Concrete Construction".

The paper was reviewed and approved by all members of the RILEM TC 260-RSC.

TC Membership:

TC Chair: Viktor Mechtcherine

TC Secretary: Mateusz Wyrzykowski

Members: Fernando C.R. Almeida, Alexander Assmann, Billy Boshoff, Daniel Cusson, João Custódio, Nele De Belie, Igor De la Varga, Kendra Erk, Vyatcheslav Falikman, Eugenia Fonseca Silva, Stefan Friedrich, Michaela Gorges, Kazuo Ichimiya, Shin-Ichi Igarashi, Agnieszka J. Klemm, Konstantin Kovler, Pietro Lura, Juhyuk Moon, Hans W. Reinhardt, António Bettencourt Ribeiro, Klaus-Alexander Rieder, Christof Schroefl, Didier Snoeck, Konstantin Sobolev, Romildo D. Toledo Filho, Nikolajs Toropovs, Chiara Vilani, Guang Ye. 


\section{Introduction}

Significant interest in superabsorbent polymers (SAPs) as a class of chemical admixtures for concrete has arisen in the past few years due to their multiple functionalities. SAPs can be applied for mitigation of autogenous and plastic shrinkage [1-3], improvement of freeze-thaw resistance [4], steering of rheological properties of fresh mixes $[5,6]$, self-sealing $[7,8]$ as well as self-healing [9,10]. Therefore, the RILEM Technical Committees (TCs) 225 SAP "Application of Superabsorbent Polymers in Concrete Construction" and 260 RSC formed to coordinate research efforts and to compile results of SAP studies. These studies mainly address the effects of SAPs on properties of concrete in its fresh and hardened states in order to prepare recommendations for its use in construction industry. In the context of these Technical Committees, a state-of-the-art report was published in 2012 [11], an international conference held in 2014 [12] and two inter-laboratory studies on mitigation of autogenous shrinkage [1] and the improvement of the freeze-thaw resistance [4] were performed.

2 SAP samples should be characterized by their sorptivity as a pre-test to estimate their 3 performance when embedded in cement-based construction materials. The reasoning for 4 performing this Round Robin Test (RRT) was to promote the use of SAPs in concrete construction by presenting simple and efficient pre-tests for practitioners and researchers. These pre-tests performed on SAP samples can disclose long-term effects of these admixtures on the properties of cement-based construction materials. By compiling the results from numerous international laboratories this paper intends to evaluate the consistency of these pre-tests independently of the particular choice of raw materials, laboratory equipment and local staff. Furthermore, it is expected that the experience from the RRT would form an integral part of the base knowledge essential for formulation of Recommendations for Practitioners, the ultimate target document of TC 260 RSC.

Depending on their molecular structure SAPs may differ significantly and characteristically in terms of swelling kinetics and final long-term storage capacity [13,14]. Besides initial intake followed by extraction due to sucking forces from the hydrating matrix $[15,16]$, SAP samples may inherently release absorbed ionic liquid for chemical reasons [17]. Both intrinsic properties may be beneficial for use in cement-based materials, i.e. to steer rheological characteristics $[5,6]$ or affect early-age drying and related plastic shrinkage. The latter topic is currently under investigation in the form of an RRT initiated by TC 260 RSC. Various test methods have been described in literature to estimate sorption kinetics of SAPs in relevant media and a recent review has been issued by members of TC 260 RSC [18]. Taking into account simplicity of tests and no need for any sophisticated lab facilities, two main test 
103 methods have evolved: the tea-bag method and the filtration method. Both methods were 104 adopted in this round-robin test. The aim was to verify the applicability of both testing 105 methods and the variability amongst different laboratories. Furthermore, the attempt was 106 made to refine whether the tea-bag method systematically overestimates the sorption capacity at a specific time as compared to the filtration method. In the course of quantifying the sorption capacity, forces causing the extraction of capillary water may be much weaker in the tea-bag method in comparison to those acting in the filtration method. This means that more inter-particle liquid may remain in the sample, which is only physically retained but not chemically adsorbed to the polymer chains in the polymer network of the particles [19]. By conducting and carefully evaluating the present RRT, this long-standing uncertainty in the community of SAP-engaged researchers should be clarified.

Besides these two methods numerous other procedures have been applied for characterization of SAP samples for use in cement-based construction materials. These two procedures as well as other experimental protocols, which have not yet been regarded in the field of concrete technology, can be found in the recent review paper [18] prepared by the TC 260 RSC.

Table 1 presents all participants of the RRT. The numbers listed in table serve as reference numbers for data obtained from the corresponding laboratories. All data was summarized and evaluated by the RRT conveners at Ghent University and TU Dresden, where also the draft of this article was prepared. The article was comprehensively discussed and agreed 
Table 1: Participants of the round-robin test

127

\begin{tabular}{|c|c|c|c|}
\hline No. & Participating institution & Principal investigator & Country \\
\hline 1 & Ghent University & Didier Snoeck & Belgium \\
\hline 2 & Technische Universität Dresden & Christof Schröfl & Germany \\
\hline 3 & $\begin{array}{l}\text { National Institute of Technology Oita } \\
\text { College }\end{array}$ & Kazuo Ichimiya & Japan \\
\hline 4 & National University of Singapore & Juhyuk Moon & Singapore \\
\hline 5 & Empa & Mateusz Wyrzykowski & Switzerland \\
\hline 6 & BCSG Trostberg & Alexander Assmann & Germany \\
\hline 7 & Kanazawa University & Shin-ichi Igarashi & Japan \\
\hline 8 & Turner-Fairbank Highway Research Center & Igor De La Varga & USA \\
\hline 9 & Glasgow Caledonian University & Agnieszka J. Klemm & United Kingdom \\
\hline 10 & Purdue University & Kendra Erk & USA \\
\hline 11 & National Laboratory for Civil Engineering & $\begin{array}{l}\text { António Bettencourt } \\
\text { Ribeiro }\end{array}$ & Portugal \\
\hline 12 & Universität Stuttgart & Hans Wolf Reinhardt & Germany \\
\hline 13 & Moscow State University & Vyatcheslav Falikman & Russia \\
\hline
\end{tabular}

\section{Materials, pre-characterization of SAP and testing liquids}

Six SAP samples, one cement sample for producing a particular test solution, tea bags and filter paper were organized and shipped to all participants by TU Dresden. Two types of SAPs called SAP 1 (crosslinked poly(acrylate-co-acrylamide) with qualitatively intermediate crosslinking density) and SAP 2 (crosslinked polyacrylate with qualitatively intermediate crosslinking density) were studied in their 'as-delivered', original grading as well as in two different particle size distributions: $<200 \mu \mathrm{m}$ and $200 \mu \mathrm{m}$ to $500 \mu \mathrm{m}$. The SAPs in their original grading were already used in previous tests. Respective nomenclatures of these polymer samples in those publications have been as follows:

- Present SAP 1 (original grading) was the one SAP used in [6], it was denominated SAP 2 in [16], SAP-DN in [5], and SAP D in [13];

- Present SAP 2 (original grading) was called SAP 1 in [1,4], SAP 1 in [16], SAP B in [5], and SAP B in [13].

In order to obtain specific required gradings the original samples were gently milled by a customary grinder (KM1310S, Tarrington House/METRO, Düsseldorf, Germany) and sieved 
at TU Dresden so that no such action was required by any other participant. Metal mesh sieves were used in the form of a sieve tower consisting of bottom, $200 \mu \mathrm{m}$ and $500 \mu \mathrm{m}$ grids. Sieving was performed until constant masses were achieved on the $200 \mu \mathrm{m}$ and the $500 \mu \mathrm{m}$ sieves, respectively. Although this procedure should result in distinct gradings, practical experience from sieving of powders in a similar way revealed that minor portions of undersize and oversize particles might still be present. As was internally confirmed by the polymer provider, the milling did not affect the fundamental chemical characteristics of the SAP samples since the particles had not been subject to post-synthesis surface treatments and temperature was below $50^{\circ} \mathrm{C}$ at any time. As agreed by all participants as well as the polymer provider, no details on the SAP samples were disclosed throughout the entire TC and RRT action. After delivery of the SAP samples to the participant, all SAP samples and other involved materials were put in a relative humidity condition of $65 \%$ and $20{ }^{\circ} \mathrm{C}$ for a minimum of two weeks. This way, any false dry weight reading should be excluded due to a possible absorption of moisture at high relative humidity.

Scanning electron microscope (SEM) images of the polymers under investigation are shown in Figure 1, the respective cumulative particle size distributions are presented in Figure 2. The SEM (JSM-7800F Prime from JEOL Ltd., Tokyo, Japan) was used to obtain the SAP images. SAP particles in dry state were distributed in double-side carbon tape and $10 \mathrm{kV}$ was used to take 30 images with $\times 30$ magnification for each SAP type under high vacuum condition. The particle size distributions in the dry state were assessed classically using laser granulometry using an LS 13320 by BeckmanCoulter, Krefeld, Germany.

67 Furthermore, two laboratories determined the particle size distribution of each SAP. The 8 calculations were based on size measurement of around 500 SAP particles to obtain reliable 69 results. One lab used the above mentioned SEM equipment and the other lab used an FEI 17 Quanta 650 environmental scanning electron microscope (ESEM). The specimens were examined using a large field detector at $5 \mathrm{kV}$ of voltage under low vacuum (50Pa). The obtained results were consistent. They indicated only minor portions of oversize or undersize grains in the respective size fractions, which can be regarded an acceptable outcome for the adopted procedures.
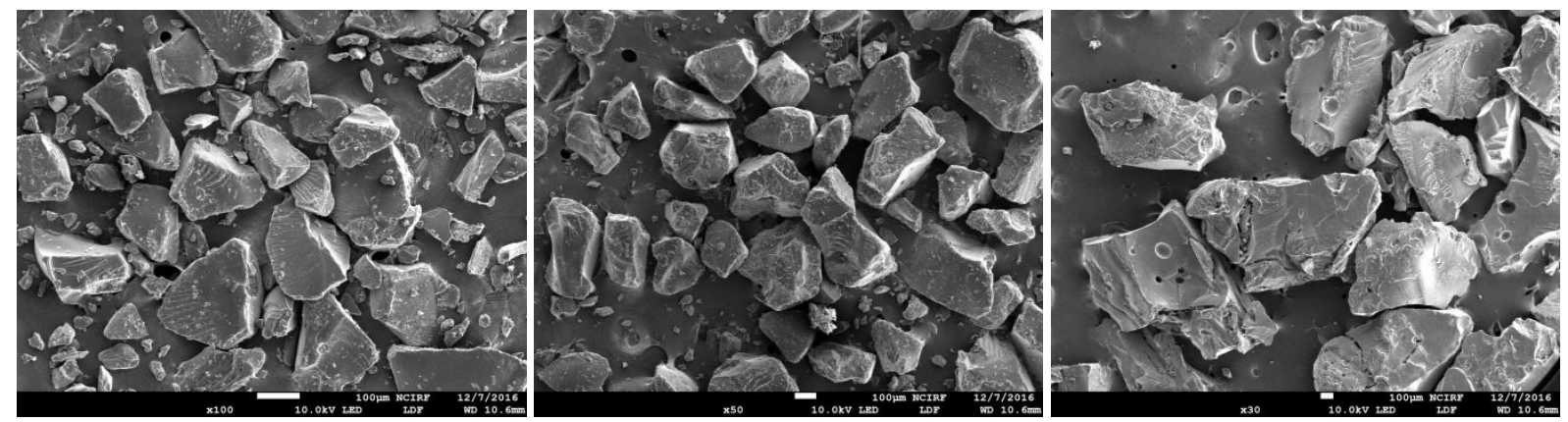
$<200 \mu \mathrm{m}$

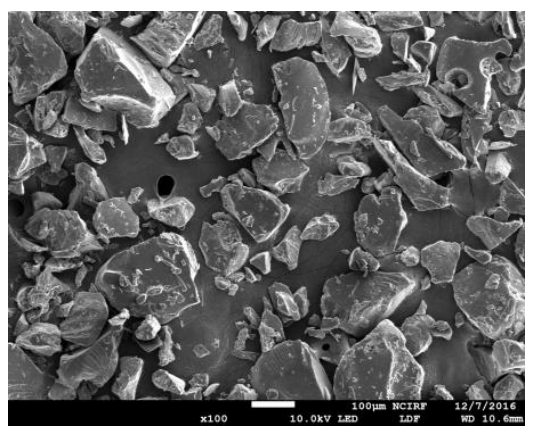

180

181

182

183

184

185 $100 \mu \mathrm{m}$.

\section{Cumulative \\ volume [\%]}

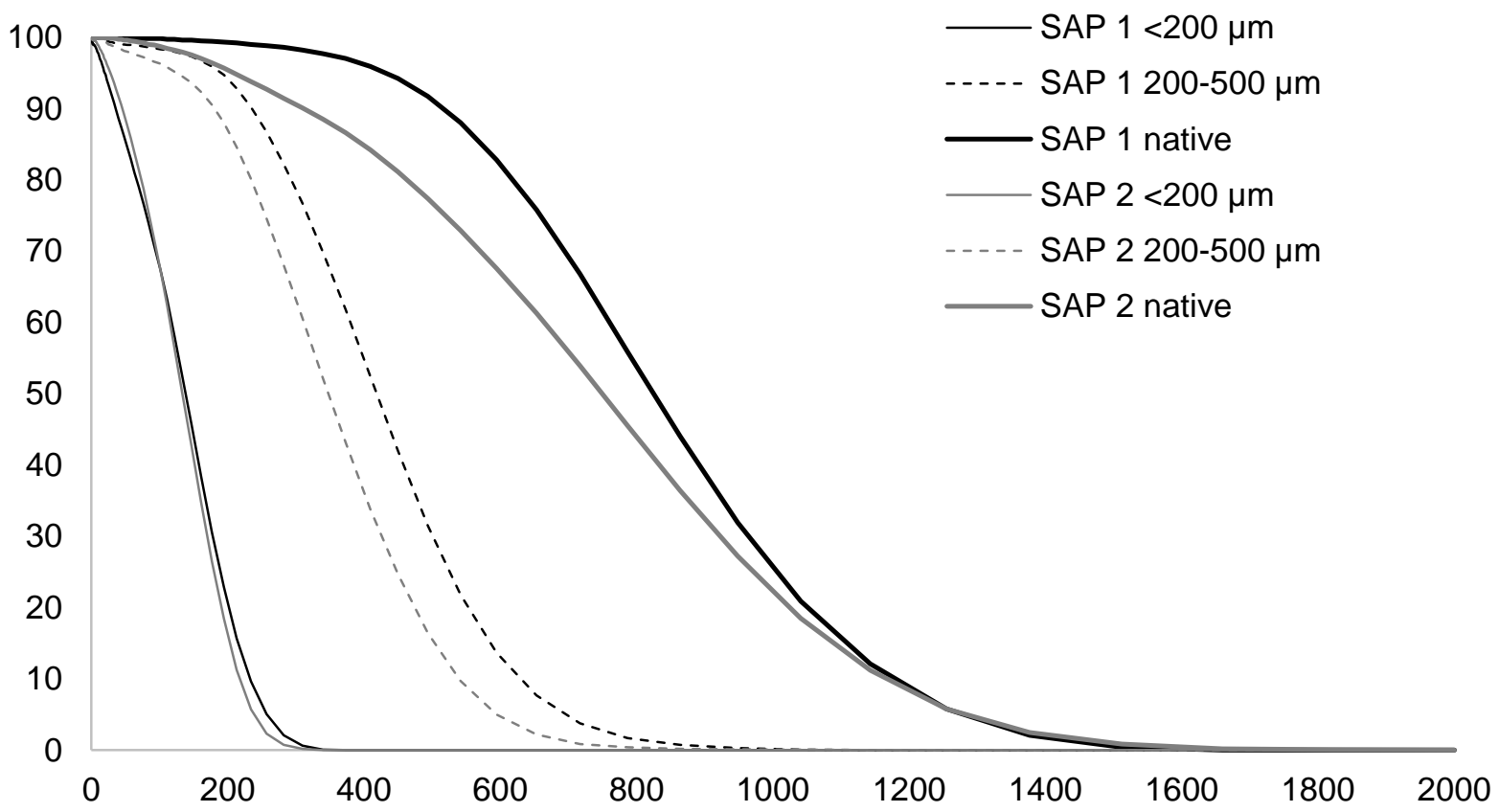

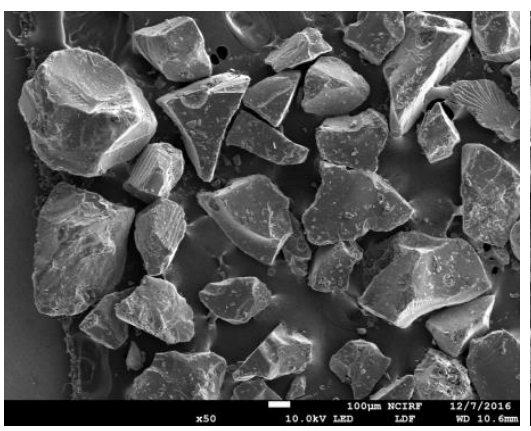

SAP 2

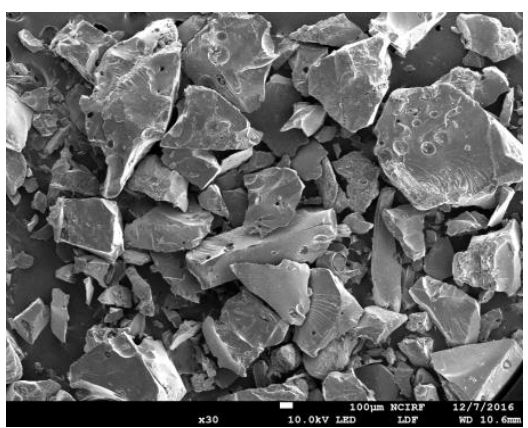

Native grading

Figure 1: Scanning electron images of the SAP samples; the scale bars amount to 
this cement in DI water with water-to-cement ratio $(\mathrm{W} / \mathrm{C})$ of $5(\mathrm{wt} / \mathrm{wt})$, immersion time 24 hours with continuous automated stirring, followed by separation of the liquid (most recommended: filtration);

3) Optional: Filtrates of other cement slurry: Each participant could select a local representative cement (Portland cement or standardized blended cement), produce a

\section{Testing methods}

\subsection{Tea-bag method}

Although the tea-bag method is described in several internationally renowned specifications exist [20-23], a distinct prescription was followed in the present RRT. From a practical point of view, this procedure was based on individual experience and common practice in participating laboratories. In the course of the RRT it turned out that it should be slightly modified prior to issuing as the RILEM recommended test procedure.

A tea-bag was pre-wetted in test fluid and its mass determined (mass $m_{2}$ ). Approximately $0.2 \mathrm{~g}$ of SAP particles were inserted, which represent the exact mass $m_{1}$. To ensure the reliability of the results, three individual tea-bags were prepared per one SAP sample. The tea-bag containing the SAP was hung in a beaker filled with the fluid (about $200 \mathrm{~mL}$ ). The beaker was tightly covered with a self-adhesive plastic stretch film quickly to avoid carbonation and evaporation. It should only be removed as shortly as feasible for each weighing. After 1 minute, 5, 10, 30, 60 minutes, 3 and 24 hours after the contact time $\mathrm{SAP} /$ liquid the tea-bag (with the hydrogel inside) was removed and weighed (mass $\mathrm{m}_{3}$ ). The tea-bag was placed on a dry cloth and gently wiped with another dry cloth for a short time of approximately 30 seconds to remove surplus and weakly bound liquid. However, in order to not disturb the sorption degree, the sample should neither be squeezed nor come into contact with the cloths longer than necessary. After weighing, the tea-bag containing the hydrogel was returned into the stock solution until the next time step of mass recording. Equation 1 provides the formula to calculate the absorption capacity (AC) at each time of reading. This primary raw data evaluation was automated in an Excel file which was provided to each participant and was returned to the conveners for further processing.

$$
A C=\frac{m_{3}-m_{2}-m_{1}}{m_{1}}
$$


where $m_{1}$ is the mass of the dry SAPs, $m_{2}$ is the mass of the pre-wetted tea-bag and $m_{3}$ is the mass of the tea-bag (with the hydrogel inside) at a specific time.

\subsection{Filtration method}

This method has been previously documented in publications $[24,10]$ and was also applied in this RRT. Similarly to the tea-bag method, during the course of the RRT it turned out that it should be slightly modified prior to issuing as a RILEM recommended test procedure. The amount of dry SAP should depend on the actual absorption capacity; there should be an excess in liquid for the polymers to freely swell to full extent. It was recommended to perform a dummy test to estimate the amount needed to take up approximately $40-50 \mathrm{~mL}$ in every studied fluid. This amount of dry SAP added was to be used in further testing.

The specific amount of dry SAP $\left(m_{1}\right)$ was inserted in a $100 \mathrm{~mL}$ beaker and approximately $100 \mathrm{~g}$ of test fluid was added $\left(\mathrm{m}_{3}\right)$. After 1 minute, 5, 10, 30, 60 minutes, 3 and 24 hours after the contact time SAP/liquid, the whole solution was filtered. To ensure that there was no influence of suction by the filter paper the latter was pre-saturated with the test fluid prior to filtration. During measurement, a lid was put on top of the filter to ensure no evaporation in time. Filtration was continued till no drops of liquid fell down anymore in subsequent intervals of one minute. The mass of filtered fluid was determined at the end $\left(m_{2}\right)$. The mass increase of the SAP was measured as the difference between the added water and the filtered water. This mass increase is a measure for the total absorption (obtained value is divided by the dry mass of the studied SAP particles). Equation 2 provides the formula to calculate the absorption capacity $(A C)$ at each time of reading. This primary raw data was evaluated in an Excel file which was provided to each participant and should be returned to the conveners for anonymous further processing. A single measurement required different container since the absorption capacity can be measured only once per sample. All measurements were performed in triplicate $(n=3)$ and neither the filtered solution nor the hydrogels were re-used.

$$
A C=\frac{m_{3}-m_{2}}{m_{1}}
$$

where $m_{1}$ is the mass of the dry SAPs, $m_{2}$ is the mass of filtered fluid at a specific time and $\mathrm{m}_{3}$ is the mass of added test fluid.

\subsection{Post-processing raw data}

A time-resolved recording of the absorption capacities is interesting in terms of the timedependent influences of the SAP, i.e. a slow or fast internal curing of the cement paste or a constant or in-/decreasing sealing effect in time. All data was collected and re-calculated 
towards the absorption capacities. These were plotted as a function of time. Furthermore, the repeatability of the results was investigated by comparing the mean of the standard deviations of all participants. The reproducibility was investigated as the standard deviation on the obtained averaged results per participant.

To investigate the different testing methods, the absorption value at $24 \mathrm{~h}$ of testing was used, as after this time a potential human error is negligible. At earlier times, a possible spread in actual testing time could also lead to a higher scatter in absorption capacities as the polymers may still absorb a high amount of testing fluid. At $24 \mathrm{~h}$, the absorption should become constant. The authors would like to mention that this $24 \mathrm{~h}$ testing value might differ for different applications. Depending on the required property, different times of swelling should be recorded; i.e. influence on porosity and autogenous shrinkage where absorption capacities of several hours are of interest, and self-sealing where absorption capacities within minutes are of importance. Depending on the application, the investigator should use the appropriate absorption capacities All data was combined and analysed as averages and 5-25-50-75-95\% intervals. All standard deviations shown are deviations on individual results. A statistical analysis was performed using the program SPSS $\AA$ in order to compare the obtained results. Multiple averages were compared using an analysis of variance (ANOVA) test with a significance level of $5 \%$. The homogeneity of the variances was controlled with a Levene's test. The post hoc test for data with homogenous variances was a Student-Newman-Keuls test and if no homogenous variances were obtained, a Dunnett's T3 test was used.

The statistical analysis was performed at Ghent University. All testing procedures and data evaluation was performed in accordance with the ASTM E691-14 standard. The following parameters were discussed: the standard deviation of the complete data set per test method and testing time $s_{\bar{x}}$, the repeatability standard deviation $s_{r}$, the between laboratory variance $s_{L}$, the reproducibility standard deviation $s_{R}$, and the consistency statistics $h$ and $k$. Following equations were used, where $p$ is the total amount of participant's per test, $\bar{x}$ the participant's average, $\overline{\bar{x}}$ the overall data average, $s$ the participant's standard deviation and $n$ the number of repetitions:

$$
\begin{gathered}
s_{\bar{x}}=\sqrt{\sum_{1}^{p} \frac{(\bar{x}-\overline{\bar{x}})^{2}}{(p-1)}} \\
s_{r}=\sqrt{\sum_{1}^{p} \frac{s^{2}}{p}}
\end{gathered}
$$




$$
\begin{gathered}
s_{L}=\sqrt{s_{\bar{x}}^{2}-\frac{s_{r}^{2}}{n}} \\
s_{R}=\sqrt{s_{L}^{2}+s_{r}^{2}} \\
h=\frac{(\bar{x}-\overline{\bar{x}})}{s_{\bar{x}}} \\
h=\frac{s}{s_{r}}
\end{gathered}
$$

\section{Experimental results}

Both SAP types were able to visually swell as shown in Figure 3. Two particles belonging to 200-500 $\mu \mathrm{m}$ fractions swelled in demineralized water and cement filtrate solution [to be added]. The fluid was added dropwise till full saturation of the particle was achieved. The process was monitored for $24 \mathrm{~h}$ by means of a stereo microscope (Leica S8 APO with DFC 295 camera).
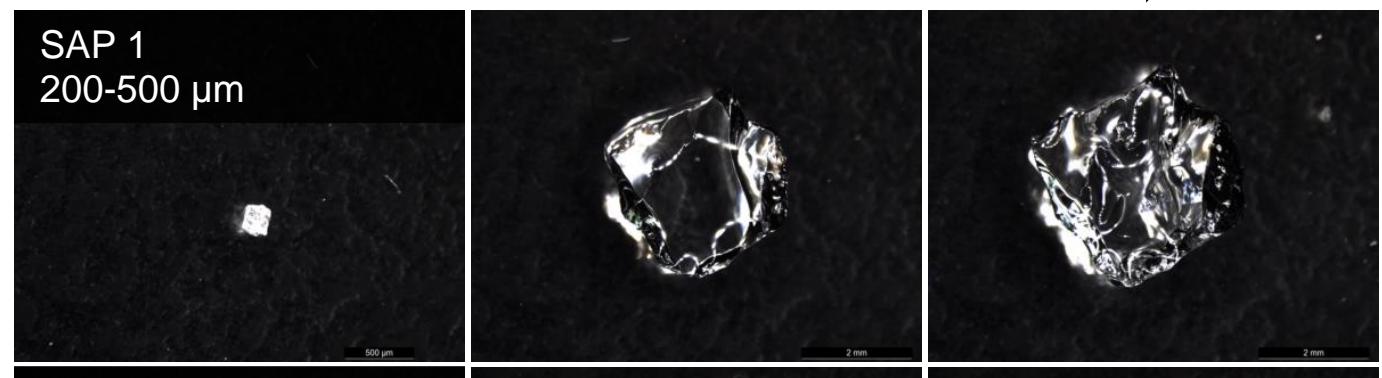

\section{SAP 2 \\ 200-500 $\mu \mathrm{m}$}

Figure 3: Swelling of the particles in demineralized water and cement filtrate solution [to be added] up to full extent as studied by means of microscopic analysis.
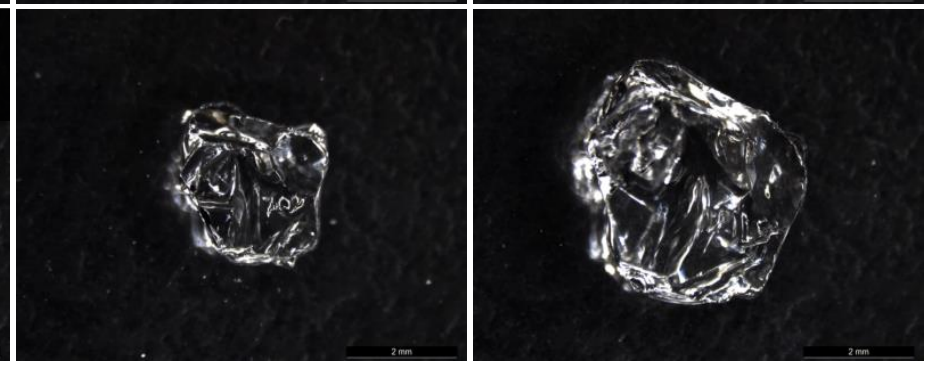

\&

\section{A}
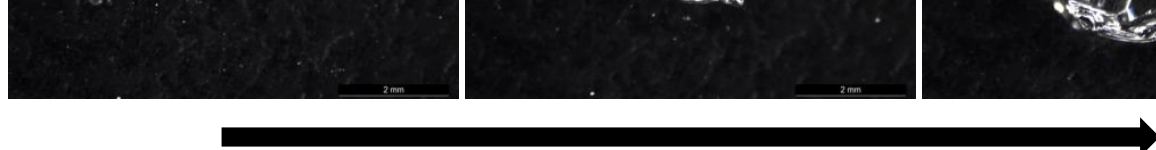
comparison of the tea-bag method and the filtration method in demineralized water for SAP 2 with a range of 200 to $500 \mu \mathrm{m}$. All other graphs for the respective testing methods and SAP types and gradings can be found in Appendix A.

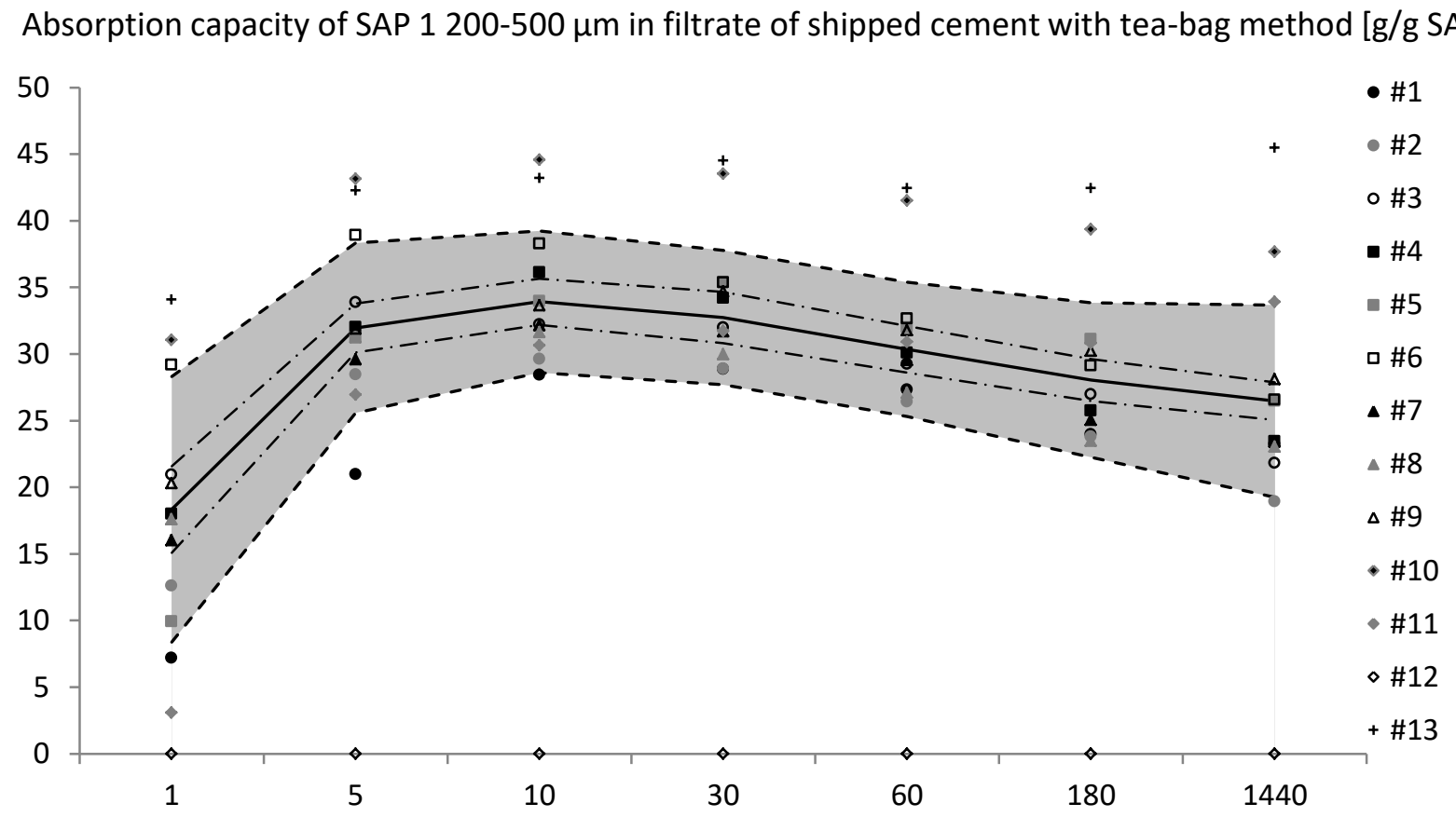

Time of water contact [min]

$315 \quad$ (a)

Absorption capacity of SAP 2 200-500 $\mu \mathrm{m}$ in filtrate of shipped cement with tea-bag method [g/g SAl

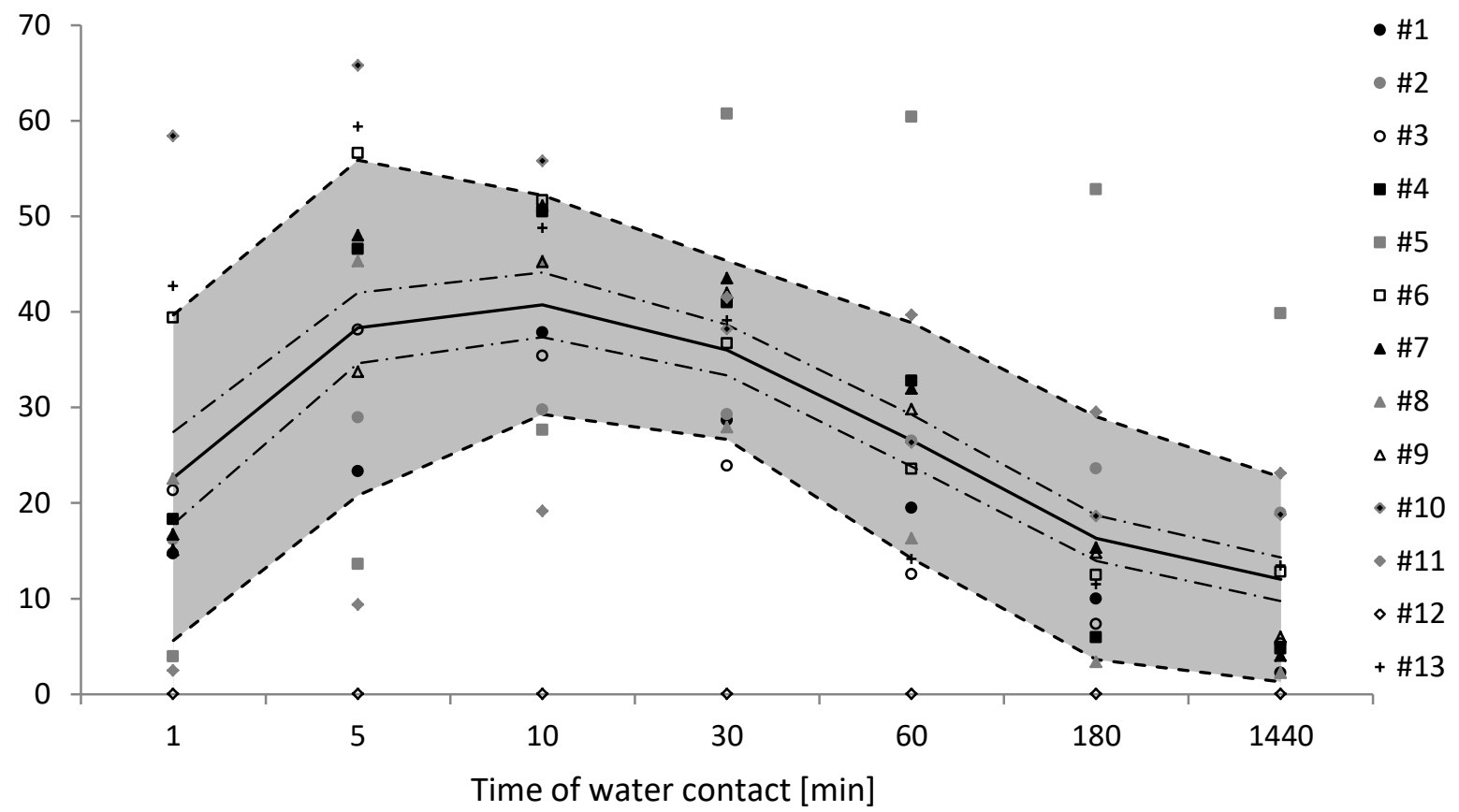


Figure 4: Absorption capacity results in cement filtrate solution by means of the tea-bag method as a function of time steps showing the average (solid lines) +/- the repeatability (dashed dotted lines) and the reproducibility (dashed lines) of SAP 1 (a) and SAP 2 (b) with 200 to $500 \mu \mathrm{m}$ grading.

Absorption capacity of SAP 2 200-500 $\mu \mathrm{m}$ in demineralized water with tea-bag method [g/g SAP]

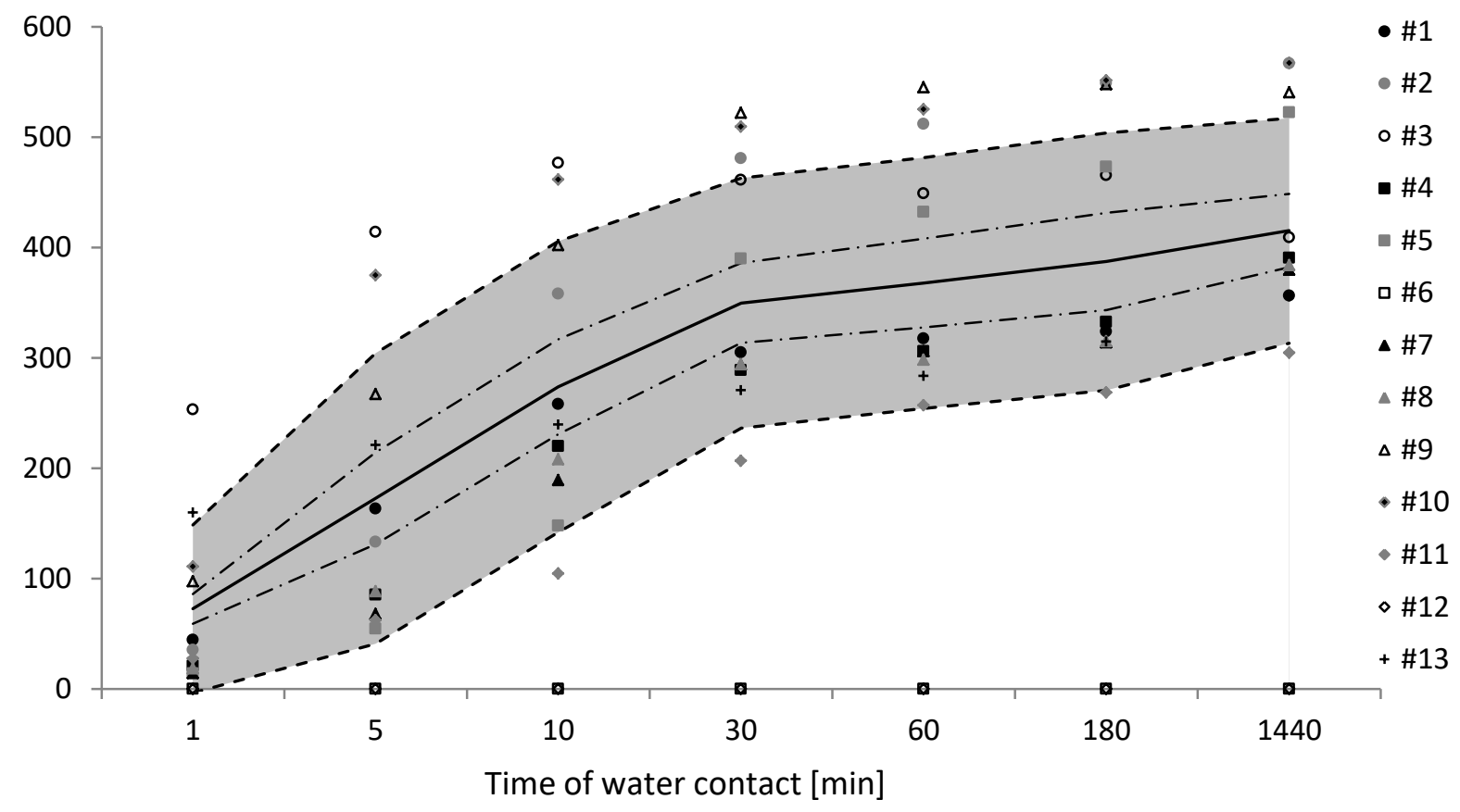

(a)

Absorption capacity of SAP 2 200-500 $\mu \mathrm{m}$ in demineralized water with filtration method [g/g SAP]

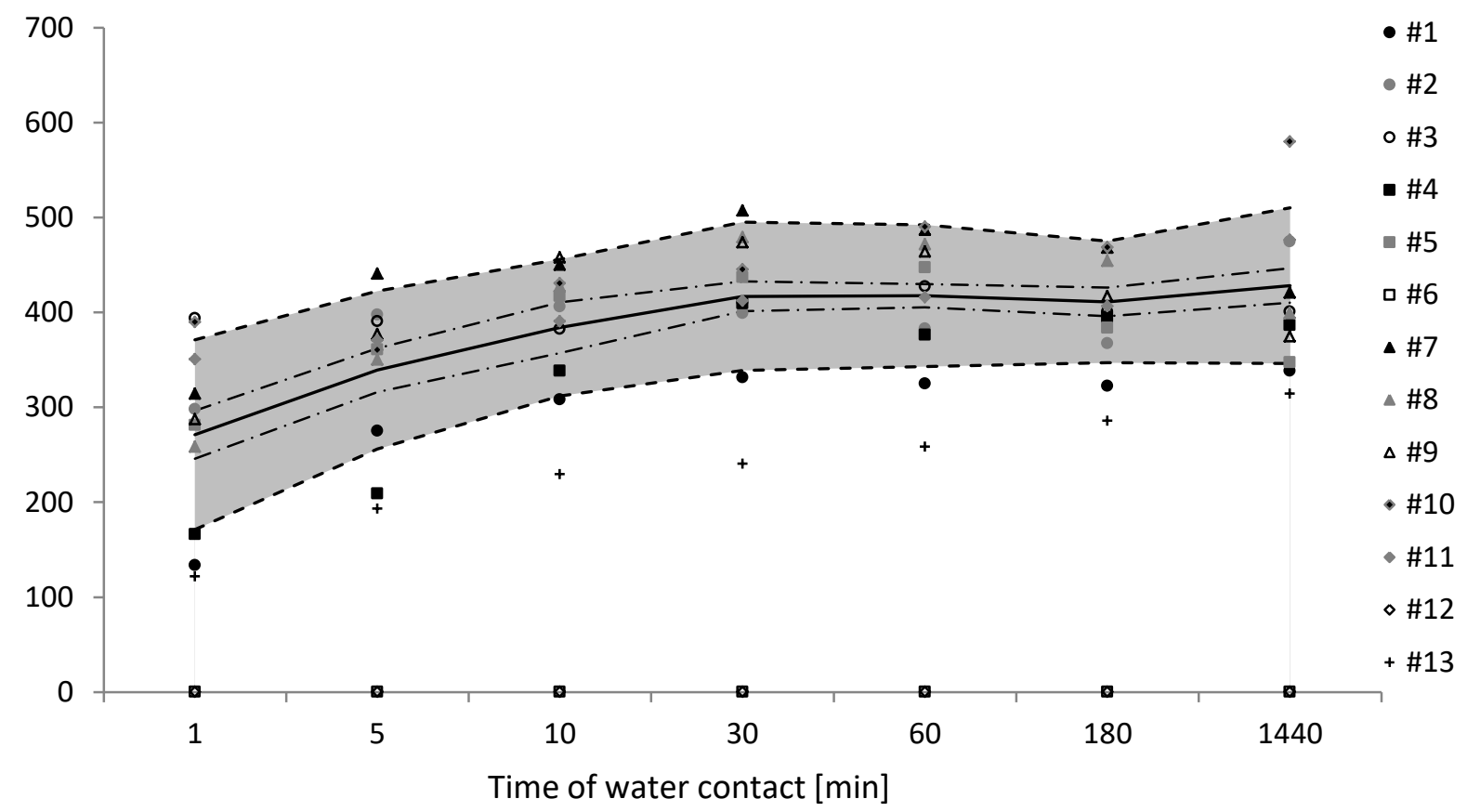

(b) 
Figure 5: Absorption capacity results of SAP 2 graded from 200 to $500 \mu \mathrm{m}$ in demineralized water by means of the tea-bag method (a) and the filtration method (b) as a function of time steps showing the average (solid lines) +/- the repeatability (dashed dotted lines) and the reproducibility (dashed lines). 


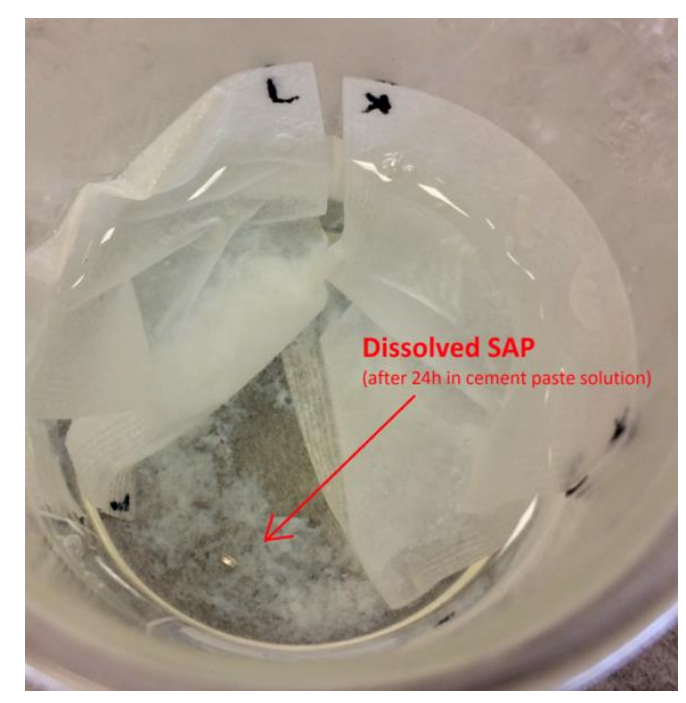

a)

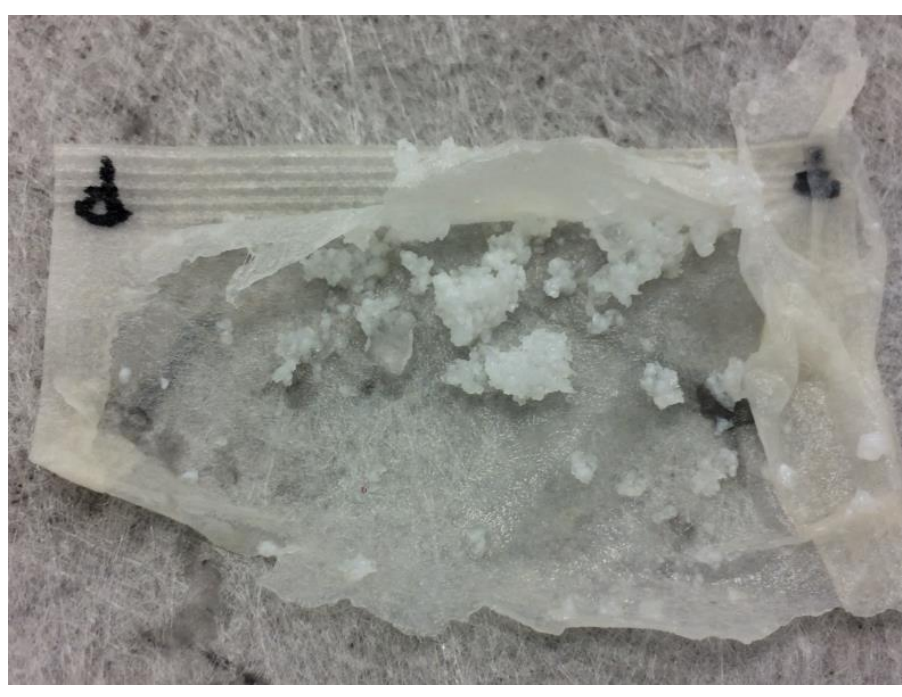

b)

Figure 6: Exemplary images made during testing of SAP 2, native grading, a) partial dissolution during the tea-bag test and b) formation of hard white particles.

Generally such a crust formation might be due to carbonation, but all test containers were sealed to minimize this effect. Only SAP 2 (all size fractions) showed this kind of reaction in the cement filtrate solution in time as reported by most participants. One participant found no decrease in absorption capacity and two found only a partial decrease. SAP 1 did not show this feature. In the short term (when SAP particles were not completely saturated, SAP 2 might have escaped from tea-bag and dissolved in the cementitious solution to minor extent. However, in long term (after 10 minutes), a predominant dissolution of SAP 2 might have taken place. When SAP 2 is placed in a highly alkaline fluid with a high ion concentration (especially with calcium ions), a hard egg-shell type of crust can be formed. Interestingly, none of these phenomena occurred in the previous studies of participant number 2 with the respective polymers $[1,4-6,13,16]$. This will be a subject of further investigation. For the time being, no chemical analyses have been performed since this would reach beyond the scope of the RRT intention. Any formulations of "dissolution" as well as "escape" of the SAPs are based on visual examination only and hence they do not provide mechanistic explanations from a chemical point of view.

However, as a first step towards clarifying the observations on a microstructural or physicochemical basis, SEM micrographs were obtained for tea-bag and filter paper used in the experimental program (Figure 7). Samples were not coated and observations were carried out with Carl Zeiss EVO 50 microscope (United Kingdom) in high vacuum mode. Images were obtained with magnification of $250 \mathrm{x}$, accelerating voltage (EHT) of $15 \mathrm{kV}$ and working distance (WD) ranges from 7.5 to $9 \mathrm{~mm}$. 


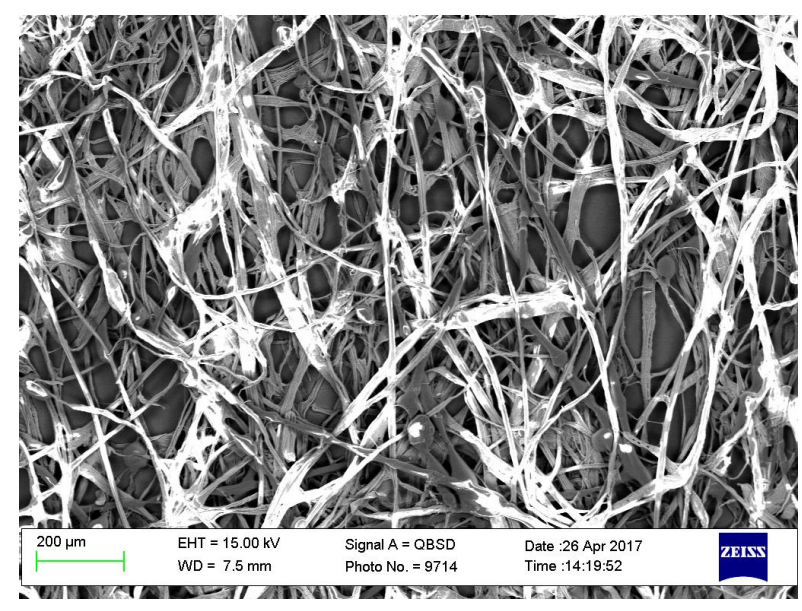

a)

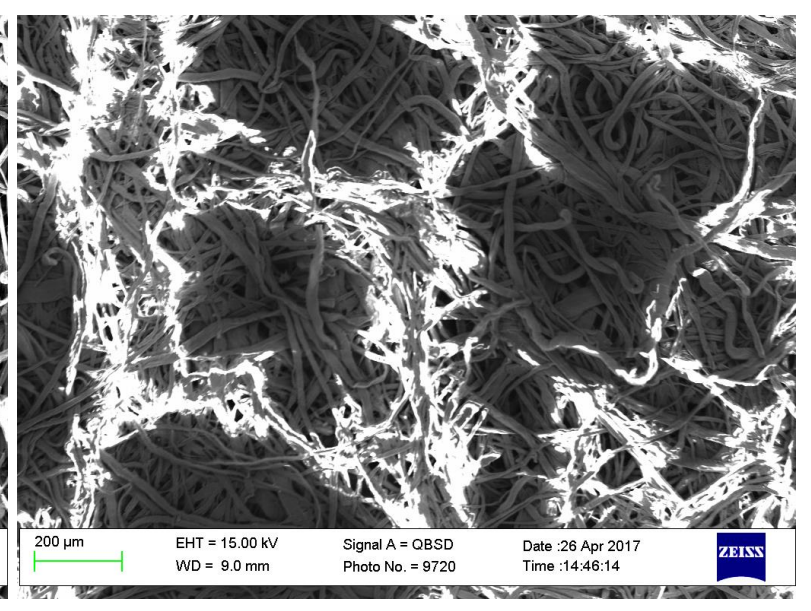

b)

Figure 7: $\quad$ SEM micrographs of the a) tea-bag fabric and b) filter paper used, showing a difference in mesh openings.

From the SEM images, it is clear that the tea-bags had a less dense mesh compared to the filter paper. This can partly explain the differences observed in swelling behaviour: the smallest particles may still be retained upon filtration, in case there is a partial dissolution. The escaping of the SAP 2 particles in the tea-bag can be explained by the larger meshes. However, upon swelling, these particles should be larger compared to the mesh size. As such, these larger particles would not escape.

High scatter in reproducibility was observed for both tests. In cement filtrate solution the scatter for both tests is in the range of $20-25 \mathrm{~g} / \mathrm{g}$. In demineralized water, the reproducibility scatter of the results was in the order of magnitude of $(172 \pm 89) \mathrm{g} / \mathrm{g}$ SAP for the tea-bag method and $(121 \pm 54) \mathrm{g} / \mathrm{g}$ SAP for the filtration method. Most likely this is due to the different operators in the different laboratories. The high scatter indicates the risk that, when testing SAPs prior to their incorporation into cementitious materials, different values obtained depending of the particular operator would lead to different concrete or mortar mixture compositions.

The repeatability per participant is again comparable per test method in cement filtrate solution; approximately $5 \mathrm{~g} / \mathrm{g}$. In demineralized water this was $57 \pm 26 \mathrm{~g} / \mathrm{g}$ SAP for the teabag method and $33 \pm 24 \mathrm{~g} / \mathrm{g}$ SAP for the filtration method.

The same trends with respect to ab- and desorption behaviour of SAPs in time were observed when testing the shipped and the locally available cement types. However, as expected the scatter of the results was larger in case of local cements.

The comparison of both test methods is shown in Figure 8 for the values obtained after 24 hours of testing. In this figure, the data is represented in box plots showing the average 
413 (middle circle 'o' in box), 25-75\% quartile intervals (box), 5-95 \% intervals (whiskers) and 414 maxima and minima (crosses ' $x$ '). Beneath the respective graphs for the absorption in the 415 shipped cement filtrate and demineralized water, the number of participants is given $(n)$. The 416 results for the local cements are given in Appendix B.

417

Absorption capacity in filtrate of shipped cement with filtration and tea-bag method [g/g SAP]

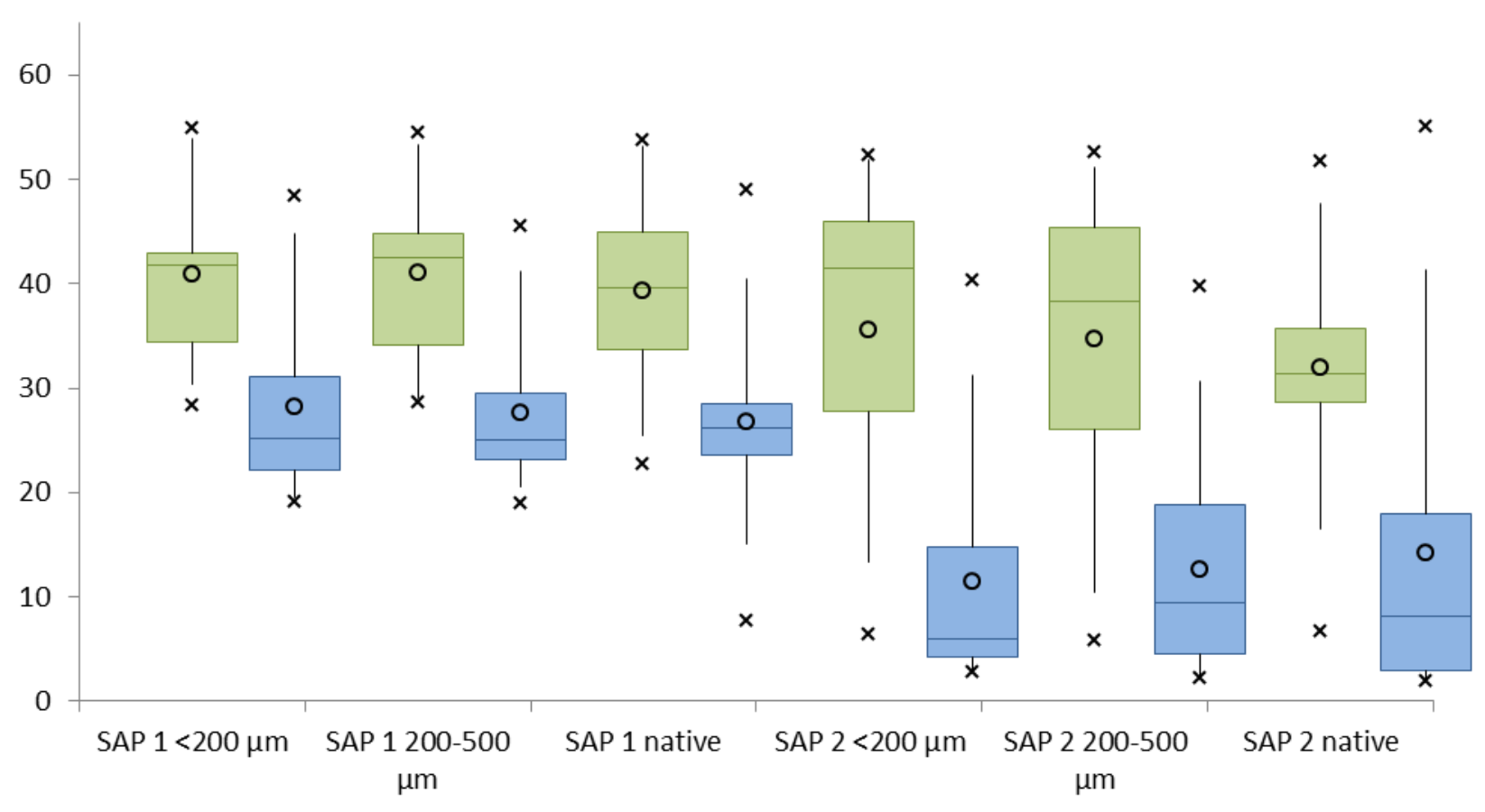

a) 


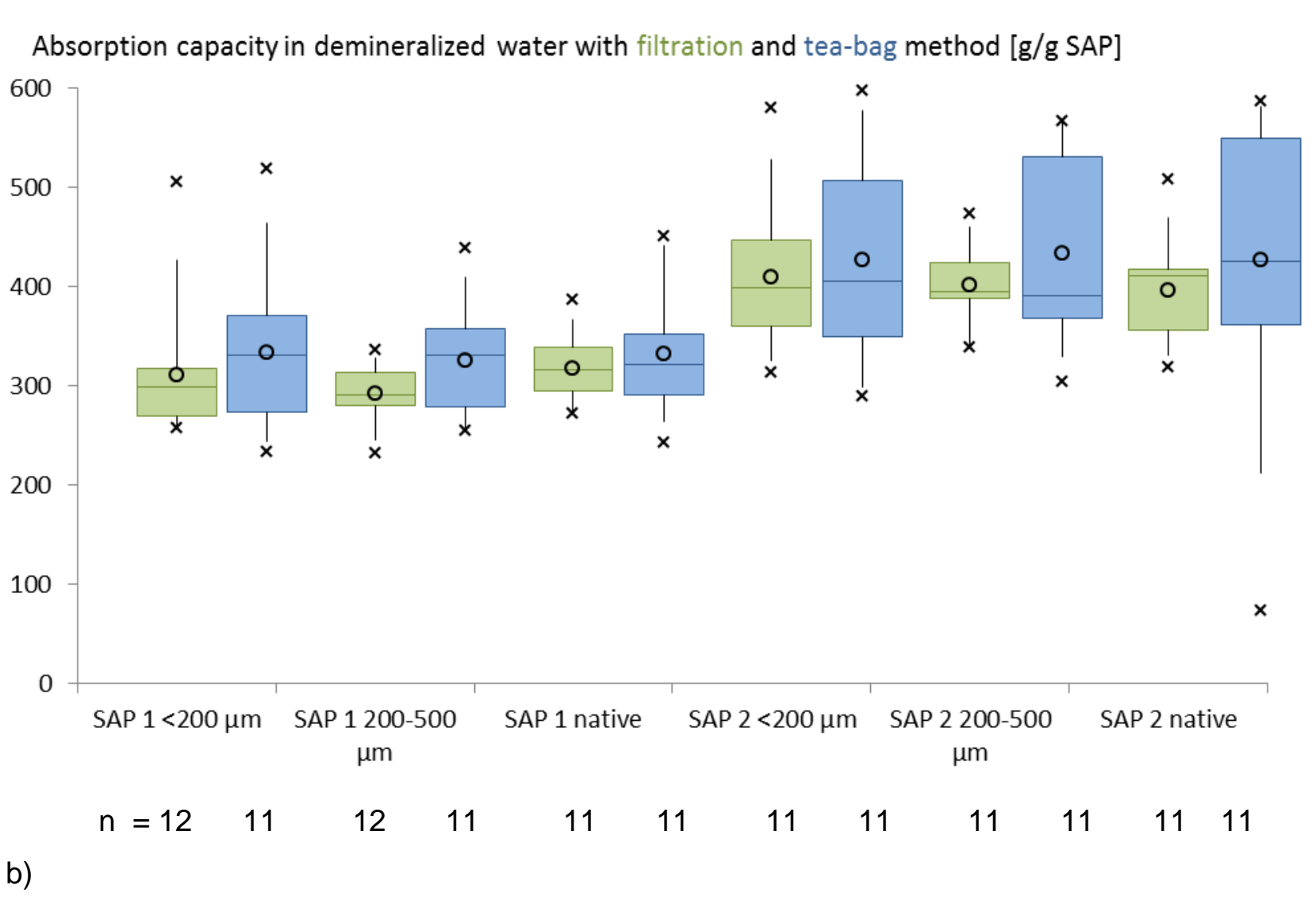

421

Figure 8: Absorption capacity after 24 hours of testing by means of the filtration and teabag methods as shown as box plots grouped per SAP type and grading: the average values (middle circle 'o' in box), 25-50-75 \% quartile intervals (box), 5$95 \%$ intervals (whiskers) and maxima and minima (crosses ' $x$ '). Beneath the respective graphs for the absorption in a) the shipped cement filtrate and b) demineralized water, the number of participants is given $(n)$.

Interestingly, the 24 hours sorptivity results in any cement filtrate solution with any SAP substance were systematically higher for the filtration method than for the tea-bag method. For SAP 1 the tea-bag results were roughly 25 to $35 \%$ below those obtained from the filtration method. This difference was even more pronounced for SAP 2 where the tea-bag results varied by approximately 25 to $45 \%$ from the filtration data.

In demineralized water, there was a very good agreement between the results from both test methods. The filtration tests showed a narrower range in obtained results and the standard deviation was smaller. A larger scatter was observed when using the tea-bag method. The values measured using the tea-bag method were on average 5 to $15 \%$ higher for SAP 1 and approximately 5 to $10 \%$ higher for SAP 2 . 
The same conclusions can be drawn from the tests in which different locally available cements were used for producing cement filtrate (results in Appendix B). The scatter is still very high, even for a lower number of participants $(n)$.

The retention capacity was calculated based on the results of sorption experiments. It was defined as the mean swelling capacity at 24 hours divided by the maximum mean swelling capacity and first calculated for each participant/SAP/testing fluid. The results are shown in Figure 9, which presents the data in box plots showing the average (middle circle 'o' in box), 25-75 \% quartile intervals (box), 5-95 \% intervals (whiskers) and maxima and minima (crosses ' $x$ '). Beneath the respective graphs for the absorption in the shipped cement filtrate and demineralized water, the number of participants is given (n). The results for the local cement can be found in Appendix B.

Retention in filtrate of shipped cement filtration and tea-bag method [\%]
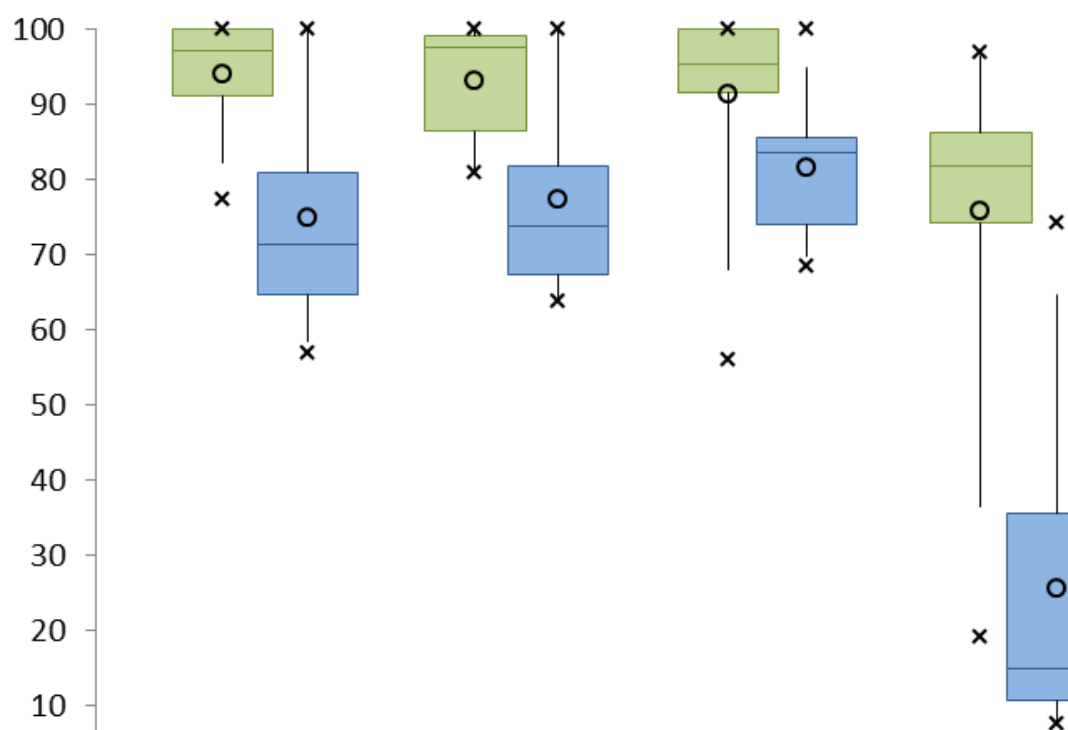

$\times$

0

$$
\text { SAP } 1<200 \mu \mathrm{m}
$$

SAP $1200-500$ $\mu \mathrm{m}$

SAP 1 native

SAP $2<200 \mu \mathrm{m}$

$\mathrm{m} \quad \mathrm{SAP}$

AP 2 200-500 $\mu \mathrm{m}$

a) 
Retention in demineralized water with filtration and tea-bag method [\%]

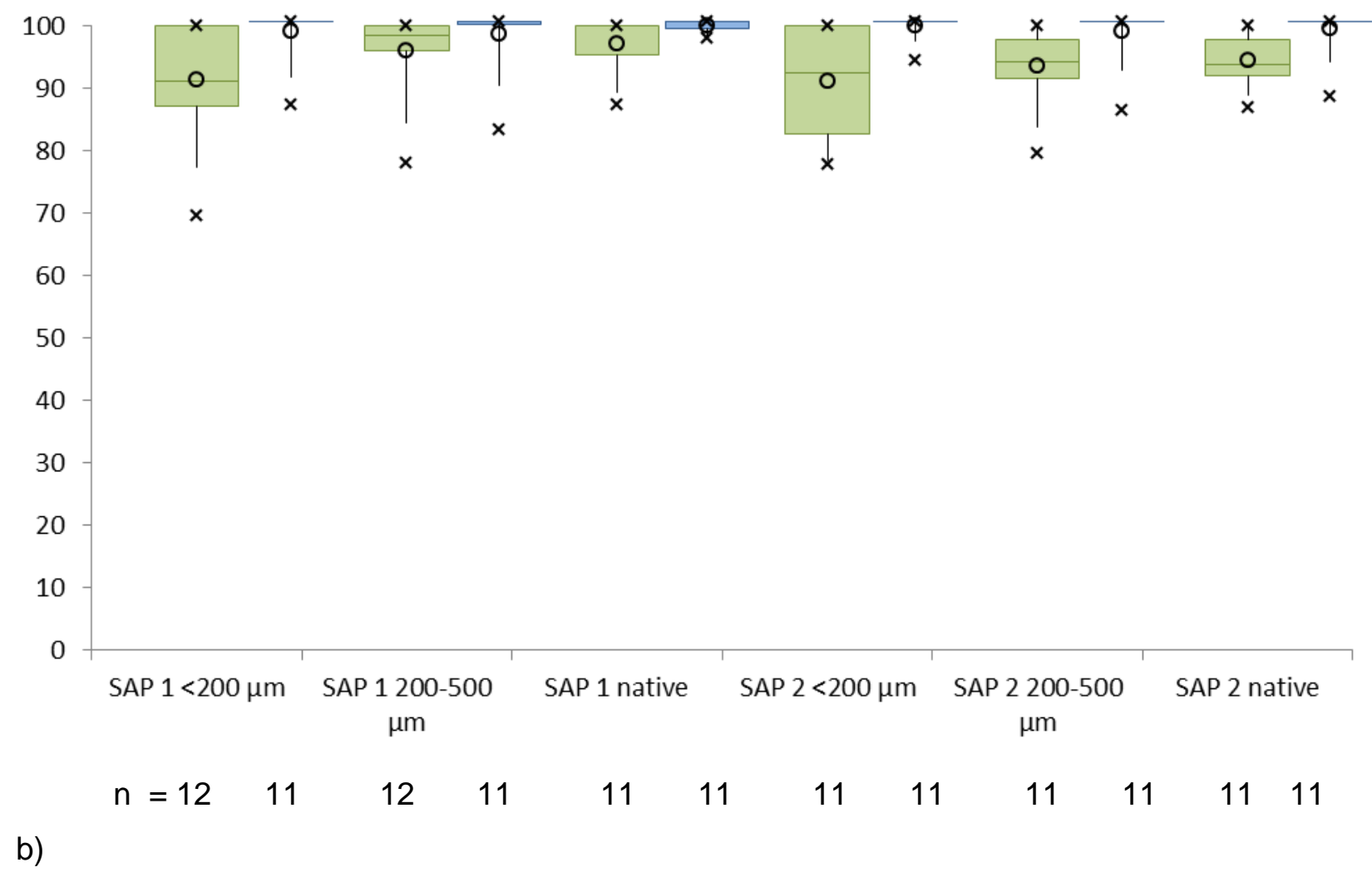

$460 \quad$ b)

Figure 9: Retention results (the 24 hours mean absorption capacity related to the maximal recorded mean absorption capacity) obtained by means of the filtration and tea-bag methods as box plots grouped per SAP type and grading: the average values (middle circle 'o' in box), 25-50-75\% quartile intervals (box), 5$95 \%$ intervals (whiskers) and maxima and minima (crosses ' $x$ '). Beneath the respective graphs for the absorption in a) the shipped cement filtrate and b) demineralized water, the number of participants is given (n).

From the retention results, it is clear that SAP 1 is able to retain the fluid for 24 hours while SAP 2 is releasing the absorbed cement filtrate solution in time. Interestingly, the extent of polymer-inherent desorption was much more pronounced in the tea-bag method opposite to the filtration method. From a point of view of polymer chemistry, the qualitative trends are as expected, i.e. SAP 1 being fairly retentive whereas SAP 2 is clearly self-releasing in the cement-derived solution. These expectations were mirrored in the tea-bag results unambiguously. On the other hand, the results from the filtration method are significantly less explicit. In demineralized water, there was practically no release of fluid by any of the SAPS under investigation. 
A high variance in operator's sensitivity was observed in the cement filtrate solution for both tests. The obtained results on the swelling capacity show a large scatter, especially for SAP 2. For the latter, most of the participants found a decrease in swelling over time. Most likely, the acrylate groups undergo complex formation with $\mathrm{Ca}^{2+}$, resulting in a) advancing the cross-linking of the primary polymer chains and b) decrease of the efficient charge density of likewise anionic groups. Such action does prominently reduce the swelling capacity in time as has previously been reported in e.g. $[6,13,14]$ and the mechanism was explained in e.g. [17]. Furthermore, chemical bonds in the polymer network may cleave, which can result in dissolution of the SAP. Most of the participants noticed a drop in absorption capacity but, interestingly, some found a steady swelling behaviour and hence, a contrary trend.

With respect to a long-lasting field of discussion, a potentially systematic drawback of the "tea-bag method" had to be clarified in the course of the Round Robin Test. For many years it has been postulated by several researchers, that residual inter-particle (capillary) liquid may remain in the samples during the wiping and weighing steps of this procedure, e.g. [19]. However, no quantification and scientifically sound proof of this critical aspect has been published up to date. Hence, the aim of this Round Robin Test was to quantitatively verify that hypothesis based on experimental results.

Considering the results obtained from the participating labs and their scatter, it can be concluded that no significant difference was found on the swelling capacity in demineralized water. The values from the tea-bag test yielded a larger scatter and were slightly (5 to 15\%) higher in comparison to the results obtained from the filtration method. Hence it is still not possible to formulate a solid conclusion on the residual inter-particle liquid discussion due to the high variability.

If both testing methods were compared to microscopic analysis (the data can be found in Appendix $\mathrm{C}$ ), it was found that in cement filtrate solution, the tea-bag method yielded lower absorption values. In demineralized water, the tea-bag method gave slightly higher values compared to the values obtained by means of microscopic analysis. The filtration method showed values around the values obtained by means of microscopic analysis.

3

One particular feature of the tea-bag method is the high variability observed in the absorptivity results. This, along with particle agglomeration issues (especially in the fine fraction) at only several tens of minutes of time, makes it difficult to properly assess the kinetics of the absorption process. Even so, the final total (within the first 24 hours) 
absorption capacity seems to be independent of the SAP fraction size, as both fine and coarse fractions exhibited similar absorption values in all cases. In between different tea-bag measurements, the time interval should be recorded and subtracted from the total measuring time. A possible error may occur as the contact times with water are changing. Even larger scatter at later ages is observed when using the teabag method compared to the filtration method.

During the experiments it became apparent that using a maximum of $0.1 \mathrm{~g}$ in the tea-bag test with DI water aided in preventing possible over-swelling of the particles. Also, the tea-bags can be sealed using a tape, which weight should be included in the dead weight during testing. The insertion of dry SAP samples in the wet tea-bag turned out to be difficult. It was more practical to put dry SAPs in dry tea-bags. The mass of water or solution absorbed by an empty tea-bag can be accounted for by calculation (i.e. considering absorption of tea-bag that came from additional measurements on 10 tea-bags).

For the filtration method, a large polymer sample is needed to conduct tests on sorption as a function of time as the sample cannot be directly reused. A possibility is to combine the method with the rising water-head test [19]. With this test, which is only usable for nonbuoyant SAP particles in a testing fluid, the settlement height of the particles is recorded in time. Using the final height measurement and the absorption capacity at $24 \mathrm{~h}$, the absorption capacities at other swelling times can be estimated. However, if one needs to record a swelling capacity at a certain time, the filtration method is preferred as the settlement may differ in time.

For some participants, the filtration method was less suitable for the determination of absorption capacity within the required filtration time. The total contact time with water should be recorded and used as the total absorption time. This time, however, is dependent on the filtration speed, SAP chemical composition, type of solution, particle size distribution, filter paper, use of vacuum filtration etc. Furthermore, the shape and size of the funnel may have an influence on the time needed to drain the mixture. This problem can be mitigated by accelerating the rate of filtration. Different strategies can be adopted to accelerate filtration such as increasing the size of the funnel and filter, use of ribbed funnels, or vacuum filtration with large surface area funnels. The filtration time required for filtering the small SAP particles is too long. Filtration can take sometimes up to 1 hour (one minute interval of consecutive drops as a criterion of filtration completion); during this time the SAP could still absorb the water or solution in the filter. Slow percolation of water through the fine particles $(<200 \mu \mathrm{m})$ of gel and potential clogging of the filter pores may lead to certain inaccuracies of the procedure. Therefore, the readings of filtered fluid mass cannot be precise, especially for measurements with short contact times of SAP and fluid. In the procedure, it was proposed 
that the filter paper would not make contact with the funnel. However, some participants made such contact, increasing the filtration time considerably. It was concluded that a hoovering filter paper or the use of a ribbed funnel could be effective in reducing filtration times. The difference in filtration (contact filter paper and funnel compared to no contact at all) amongst the participants accounted for the observed high scatter and the practical problems. These were taken into account in the overall recommendation, as prepared within this TC.

The decrease in swelling behaviour for SAP 2 was clearly observed in the tea-bag method and not in the filtration method. This could be potentially attributed to inadequately sealed condition during the tea-bag method compared to the filtration method. However, all participants were instructed to properly seal the containers during storage. Another reason could be the difference in mesh size of the tighter filtration paper compared to the more open tea-bag, leading to clogging. A further reason can be cleavage of chemical bonds in the polymer structure due to the high alkaline $\mathrm{pH}$ value or other ions present in the test liquid. As an example, some ester bonds can be prone to hydrolysis when exposed to cement filtrate for a longer time. Although not verified instrumental chemical analysis, visual observations by numerous participants indicate that the hydrogel particles in fact dissolve over time. This clearly indicates that the hydrated polymeric networks disintegrate into solutes. Such dissolution results in practically invisible polymer and the suspensions with the swollen SAPs look like clear solutions.

Apart from this, partial carbonation during measuring and dampening the tea-bags might give reason to the de-swelling. As carbon dioxide dissolves in the highly alkaline solution, the $\mathrm{pH}$ value drops to a small but still notable extent. Consequently, potentially intermediately precipitated $\mathrm{Ca}^{2+}$ ions re-dissolve, enter the hydrogels, bind intensely to the carboxylate moieties and in this way promote and support the principal de-swelling mechanism that was explained at the beginning of the Discussion Section. SAP 2, due to its higher density of carboxylate groups along the primary chains as compared to SAP 1, may be expected to be more prone to such behaviour.

Irrespective of the chemical mechanisms behind de-swelling or potential partial dissolution, care should be taken to minimize the contact time of SAPs with the environmental conditions. This way, hydrogel-inherent characteristics can be elucidated without producing interfering products.

By using the statistical analysis as described in ASTM E691-14, following values for the different standard deviations, repeatability and reproducibility could be found. Table 2 shows 
that the results per grading are comparable to each other so the average for individual SAPs

In cement filtrate solution, both methods show approximately the same repeatability and

\section{Summary and conclusions \\ 6. Summary and conclusions}

Table 2: The standard deviation of the complete data set per test method and testing time $s_{\bar{x}}$, the repeatability standard deviation $s_{r}$, the between laboratory variance $s_{L}$ and the reproducibility standard deviation $s_{R}$ for both tests following ASTM

\begin{tabular}{l|cccc|cccc}
\hline & \multicolumn{4}{|c|}{ Tea-bag method } & \multicolumn{4}{c}{ Filtration method } \\
& $\boldsymbol{s}_{\overline{\boldsymbol{x}}}$ & $\boldsymbol{s}_{\boldsymbol{r}}$ & $\boldsymbol{s}_{\boldsymbol{L}}$ & $\boldsymbol{s}_{\boldsymbol{R}}$ & $\boldsymbol{s}_{\overline{\boldsymbol{x}}}$ & $\boldsymbol{s}_{\boldsymbol{r}}$ & $\boldsymbol{s}_{\boldsymbol{L}}$ & $\boldsymbol{s}_{\boldsymbol{R}}$ \\
\hline Cement filtrate solution SAP 1 & 8.6 & 1.9 & 8.6 & 8.8 & 10.7 & 4.8 & 10.2 & 11.6 \\
Cement filtrate solution SAP 2 & 12.7 & 3.1 & 12.5 & 12.9 & 15.1 & 9.9 & 14.0 & 17.2 \\
Demineralized water SAP 1 & 68.0 & 22.8 & 66.7 & 70.6 & 43.9 & 14.6 & 43.0 & 45.5 \\
Demineralized water SAP 2 & 124.9 & 62.8 & 119.1 & 135.6 & 57.4 & 17.1 & 56.6 & 59.1 \\
\hline
\end{tabular}
reproducibility. In demineralized water, however, the scatter in the tea-bag method is higher compared to the filtration method. This is due to both a higher scatter in obtained averages per participant $\boldsymbol{s}_{\overline{\boldsymbol{x}}}$ and the participants own repeatability standard deviation $\boldsymbol{s}_{\boldsymbol{r}}$. This is reflected in the laboratory variances $s_{L}$ and the reproducibility standard deviation $s_{R}$. The same conclusions as stated above following from a visual study of the obtained graphs can be made.

If zooming into the individual results, the graphs of the consistency statistics $h$ and $k$ can be found in Appendix D. From the consistency statistics results, it is clear that most of the participants show coherent data when performing both tests. The standard deviations are acceptable and comparable. This data shows the relative position of each participant in the $\mathrm{RRT}$ test and is thus disclosed as complementary data.

In this Round Robin Test, the absorption capacity of two different SAP types was tested in different solutions and by two testing methods in order to assess the suitability of these methods to estimate quality of SAP as concrete admixture. The testing methods were the tea-bag method and the filtration method. The tests were performed within the framework of the activities of the RILEM Technical Committee 260 RSC "Recommendations for use of superabsorbent polymers in concrete construction" by 13 laboratories. 
The results obtained from all participants were found to be consistent with respect to the sorption behaviour of the SAPs even though high scatter was observed at early ages. The tea-bag method proved to be more practical in terms of time, while the filtration method showed less variation in the absorption capacity after 24 hours. Furthermore, polymerinherent desorption of cement pore solution (as compared to long-term retention) could be estimated by the tea-bag method clearly, whereas the filtration method could not disclose such behaviour to the same extent within the time frame of the testing period up to 24 hours

\section{Acknowledgements}

As a Postdoctoral Research Fellow of the Research Foundation-Flanders (FWO(12J3617N). 
Prof. Juhyuk Moon wants to thank Dr. Sung-Hoon Kang for the experimental work. Prof. Mechtcherine and Dr. Schröfl thank Paul Mai for preparing and shipping the polymer samples and Olga Pertseva for performing the sorption experiments. F.C.R. Almeida acknowledges National Council for Scientific and Technological Development (CNPq - Brazil) for the financial support.

\section{References}

1. Mechtcherine V, Gorges M, Schröfl C, Assmann A, Brameshuber W, Bettencourt Ribeiro V, Cusson D, Custódio J, Fonseca da Silva E, Ichimiya K, Igarashi S, Klemm A, Kovler K, Lopes A, Lura P, Nguyen VT, Reinhardt HWTF, R.D., Weiss J, Wyrzykowski M, Ye G, Zhutovsky S (2014) Effect of Internal Curing by Using Superabsorbent Polymers (SAP) on Autogenous Shrinkage and Other Properties of a High-performance Fine-grained Concrete: Results of a RILEM Round-robin Test, TC 225-SAP. Mater Struct 47 (3):541-562

2. Jensen OM, Hansen PF (2001) Water-entrained cement-based materials I. Principles and theoretical background. Cem Concr Res 31 (4):647-654

3. Jensen OM, Hansen PF (2002) Water-entrained cement-based materials II. Experimental observations. Cem Concr Res 32 (6):973-978

4. Mechtcherine V, Schröfl C, Wyrzykowski M, Gorges M, Cusson D, Margeson J, De Belie N, Snoeck D, Ichimiya K, Igarashi S-I, Falikman V, Friedrich S, Bokern J, Kara P, Lura P, Marciniak A, Reinhardt H-W, Sippel S, Ribeiro AB, Custódio J, Ye G, Dong H, Weiss J (2017) Effect of superabsorbent polymers (SAP) on the freeze-thaw resistance of concrete: results of a RILEM interlaboratory test. Mater Struct 50 (14):1-19. doi:10.1617/s11527-0160868-7

5. Mechtcherine V, Secrieru E, Schröfl C (2015) Effect of superabsorbent polymers (SAPs) on rheological properties of fresh cement-based mortars - Development of yield stress and plastic viscosity over time. Cem Concr Res 67:52-65. doi:10.1016/j.cemconres.2014.07.003 6. Secrieru E, Mechtcherine V, Schröfl C, Borin D (2016) Rheological characterisation and prediction of pumpability of strain-hardening cement-based composites (SHCC) with and without addition of superabsorbent polymers (SAP) at various temperatures. Constr Build Mater 112:581-594

7. Snoeck D, Steuperaert S, Van Tittelboom K, Dubruel P, De Belie N (2012) Visualization of water penetration in cementitious materials with superabsorbent polymers by means of neutron radiography. Cem Concr Res 42 (8):1113-1121. doi:10.1016/j.cemconres.2012.05.005 
8. Lee HXD, Wong HS, Buenfeld NR (2010) Potential of superabsorbent polymer for selfsealing cracks in concrete. Adv Appl Ceram 109 (5):296-302

9. Snoeck D, Dewanckele J, Cnudde V, De Belie N (2016) X-ray computed microtomography to study autogenous healing of cementitious materials promoted by superabsorbent polymers. Cem Concr Comp 65:83-93

10. Snoeck D, Van Tittelboom K, Steuperaert S, Dubruel P, De Belie N (2014) Self-healing cementitious materials by the combination of microfibres and superabsorbent polymers. $J$ Intel Mat Syst Str 25 (1):13-24. doi:10.1177/1045389X12438623

11. 225-SAP (2012) Application of Superabsorbent Polymers (SAP) in Concrete Construction. RILEM State-of-the-Art Report Prepared by Technical Committee 225-SAP. doi:10.1007/978-94-007-2733-5

12. Mechtcherine V, Schröfl C (2014) RILEM Proceedings PRO 95: Application of superabsorbent polymers and other chemical admixtures in concrete construction. RILEM Publications S.A.R.L., Bagneux

13. Schröfl C, Mechtcherine V, Gorges M (2012) Relation between the molecular structure and the efficiency of superabsorbent polymers (SAP) as concrete admixture to mitigate

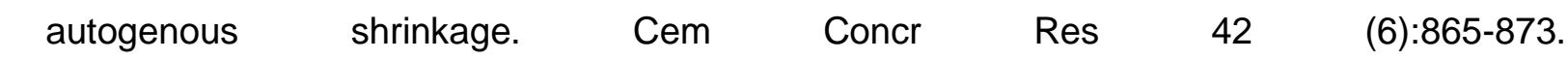
doi:10.1016/j.cemconres.2012.03.011

14. Krafcik MJ, Erk KA (2016) Characterization of superabsorbent poly(sodium-acrylate acrylamide) hydrogels and influence of chemical structure on internally cured mortar. Mater Struct 49 (11):4765-4778

15. Wyrzykowski M, Lura P, Pesavento F, Gawin D (2011) Modeling of internal curing in maturing mortar. Cem Concr Res 41 (12):1349-1356

16. Schröfl C, Mechtcherine V, vontobel P, Hovind J, Lehmann E (2015) Sorption kinetics of superabsorbent polymers (SAPs) in fresh Portland cement-based pastes visualized and quantified by neutron radiography and correlated to the progress of cement hydration. Cem Concr Res 75:1-13. doi:10.1016/j.cemconres.2015.05.001

17. Richter A, Paschew G, Klatt S, Lienig J, Arndt K-F, Adler H-JP (2008) Review on hydrogel-based pH sensors and microsensors. Sensors 8 (1):561-581

18. Schröfl C, Snoeck D, Mechtcherine V (2017) A review of characterisation methods for superabsorbent polymer (SAP) samples to be used in cement-based construction materials Report of the RILEM TC 260-RSC. Mater Struct 50 (197):1-19. doi:10.1917/s11527-0171060-4

19. Jensen OM Water absorption of superabsorbent polymers in a cementitious environment. In: Leung CKY, Wan KT (eds) International RILEM Conference on Advances in Construction Materials through Science and Engineering, Hong Kong SAR, 2011. RILEM Publications S.A.R.L., pp 22-35 
729 20. EDANA (2002) EDANA recommended test methods. Brussels

730 21. JIS JIS (1996) Testing method for water absorption rate of super absorbent polymers.

731 JIS K 7224.

732 22. JIS JIS (1996) Testing method for water absorption capacity of super absorbent 733 polymers. JIS K 7223.

734 23. EDANA, INDA (2011) Standard test method for polyacrylate superabsorbent powders, 735 determination of the free swell capacity in saline by gravimetric measurement.

736 24. Snoeck D (2015) Self-Healing and Microstructure of Cementitious Materials with 737 Microfibres and Superabsorbent Polymers. Ghent University, Ghent 

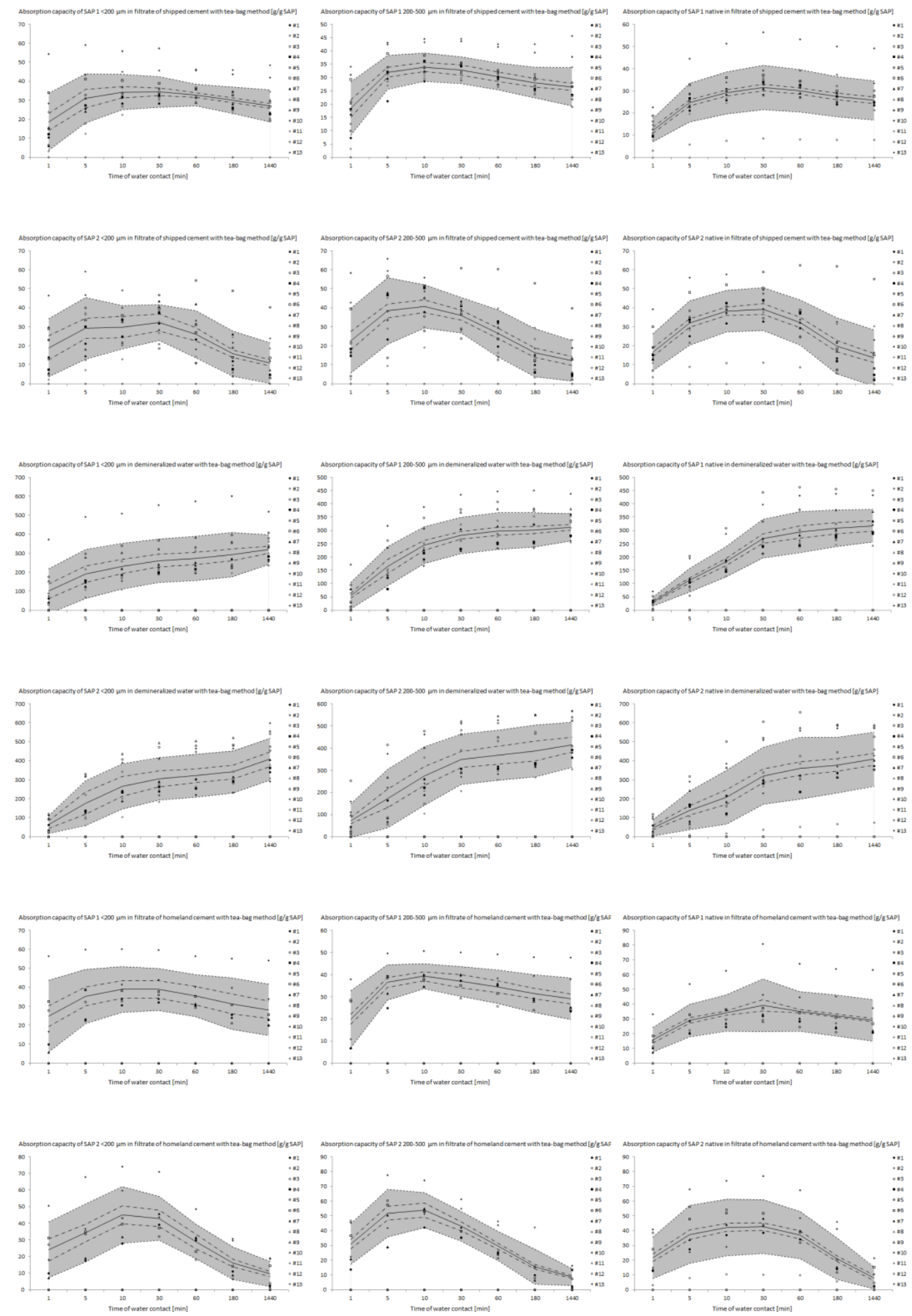

Figure 10: Absorption capacity results by means of the tea-bag method as a function of time steps showing the average and the average (solid lines) $+/$ - the repeatability (dashed dotted lines) and the reproducibility (dashed lines). 

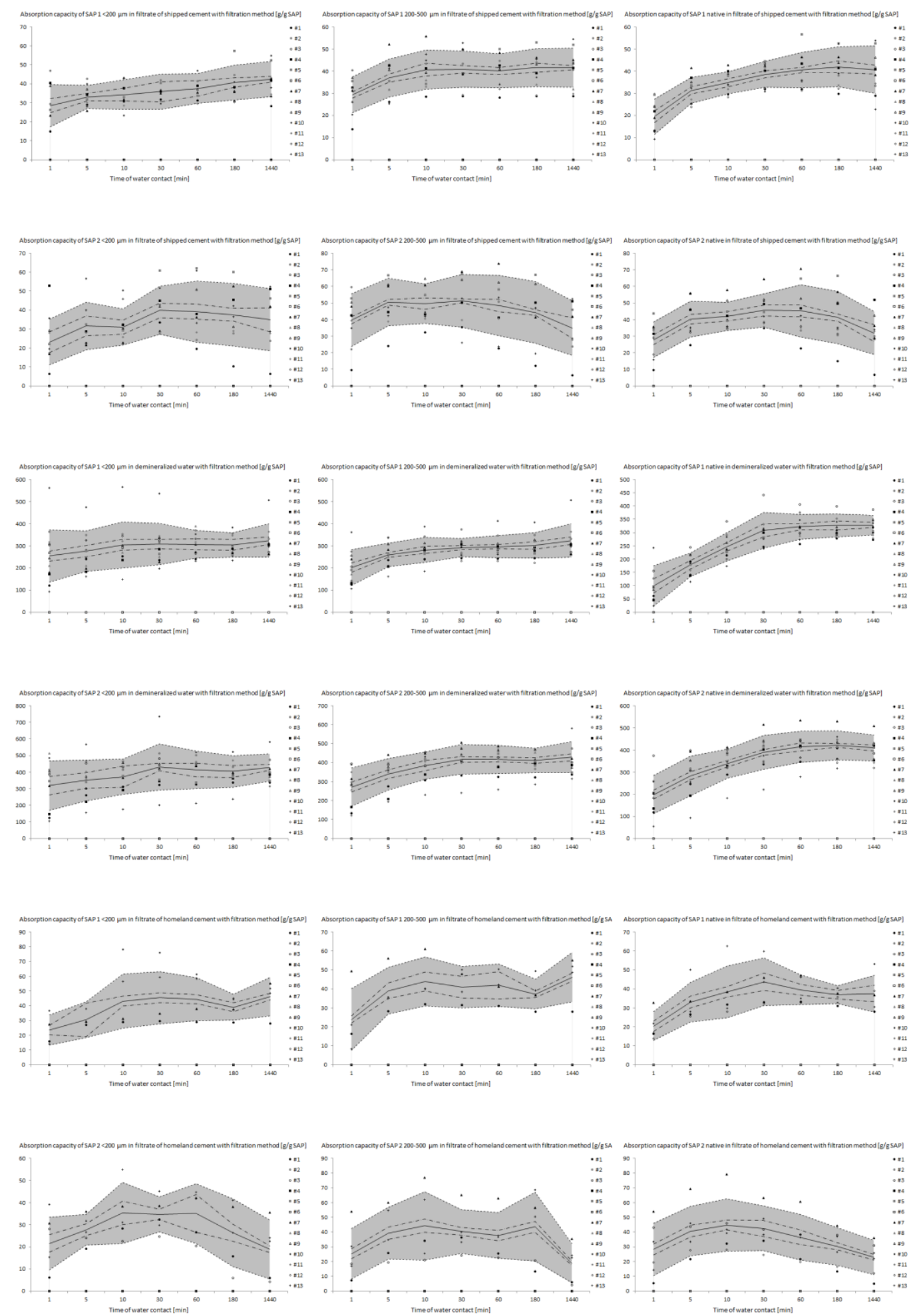

Figure 11: Absorption capacity results by means of the filtration method as a function of 750 time steps showing the average and the average (solid lines) +/- the repeatability (dashed dotted lines) and the reproducibility (dashed lines). 
Absorption capacity in filtrate of homeland cement with filtration and tea-bag method $[\mathrm{g} / \mathrm{g}$ SAP]
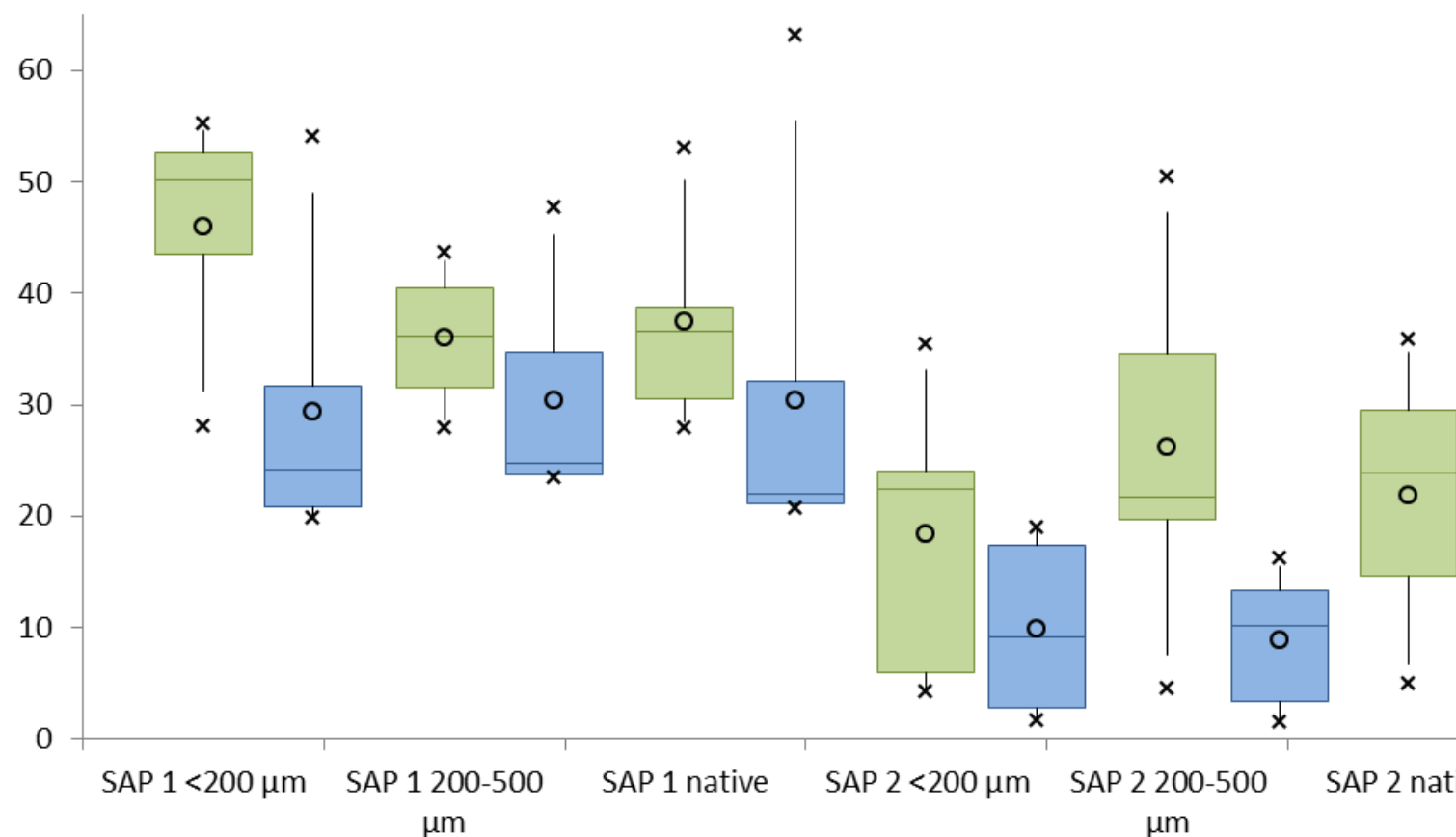

$\circ$

$\mathrm{n}=4 \quad 6 \quad 4 \quad 6$

5

7

56

56

$\begin{array}{ll}6 & 7\end{array}$

Figure 12: Absorption capacity after 24 hours of testing by means of the filtration and teabag methods as shown as box plots grouped per SAP type and grading: the average values (middle circle 'o' in box), 25-50-75 \% quartile intervals (box), 5$95 \%$ intervals (whiskers) and maxima and minima (crosses ' $x$ '). Beneath the respective graphs for the absorption in the homeland cement, the number of participants is given (n). 
Retention in filtrate of homeland cement with filtration and tea-bag method [\%]

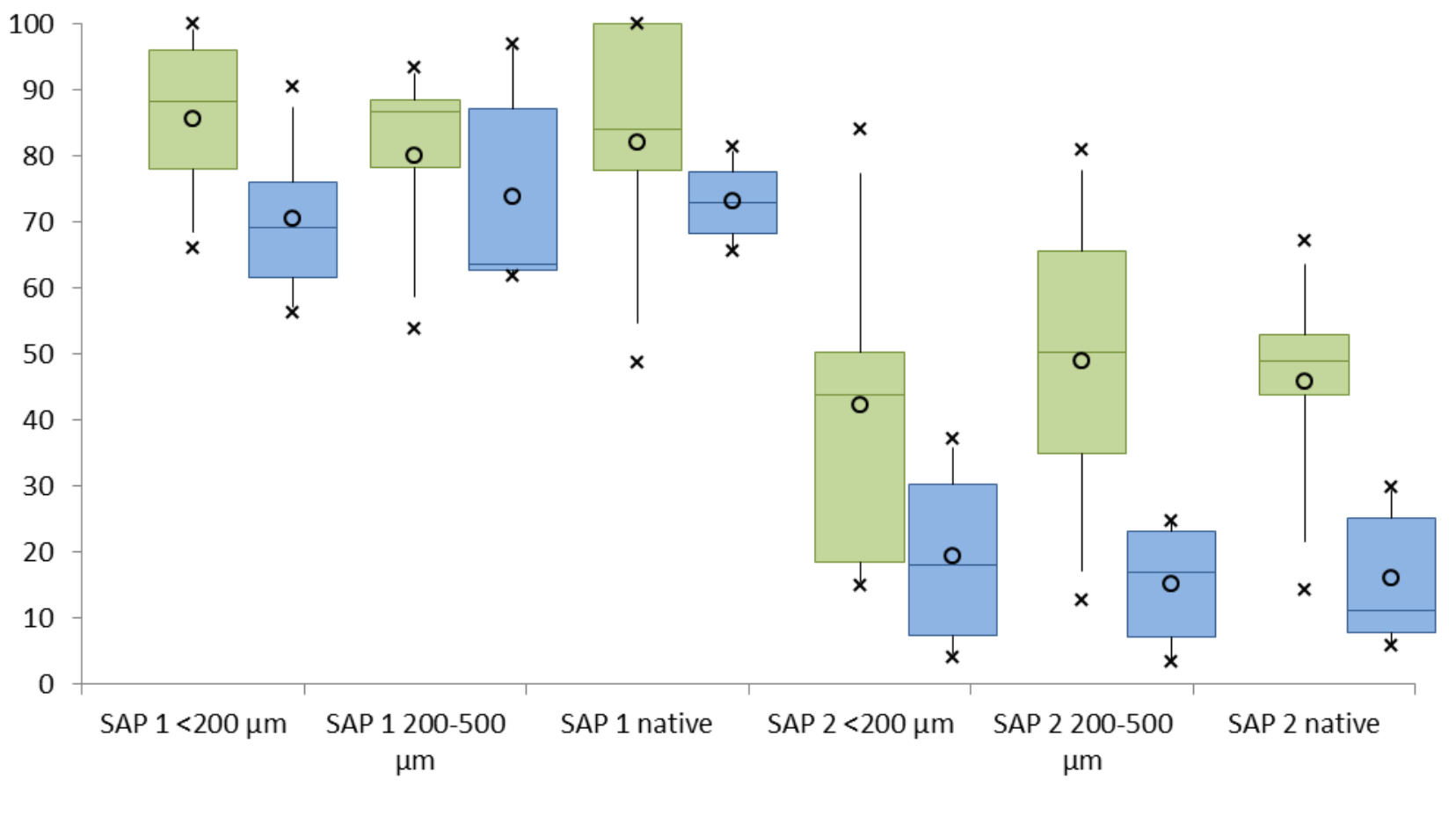

Figure 13: Retention results (the 24 hours mean absorption capacity related to the maximal recorded mean absorption capacity) obtained by means of the filtration and tea-bag methods as box plots grouped per SAP type and grading: the average values (middle circle 'o' in box), 25-50-75 \% quartile intervals (box), 5$95 \%$ intervals (whiskers) and maxima and minima (crosses ' $x$ '). Beneath the respective graphs for the absorption in the homeland cement, the number of participants is given $(n)$. 
Different methods could be compared. These were the tea-bag method, the filtration method, the rising head method [19] and the microscopic analysis. Assuming perfect spherical SAPs and estimating the average diameter of the dry and saturated particle, the absorption capacity could be determined by microscopic analysis. It is true that the estimated diameter of a spherical particle is not the size of the irregular particle, but a first estimation of the swelling capacity can be made. Another estimation was the density, which was put at 1400 $\mathrm{kg} / \mathrm{m}^{3}$ of SAP. The results are found in Figure 14 and Figure 15 for the filtrate of the cement slurry of the shipped cement and demineralized water, respectively. The values shown are the ones after 24 hours of testing.

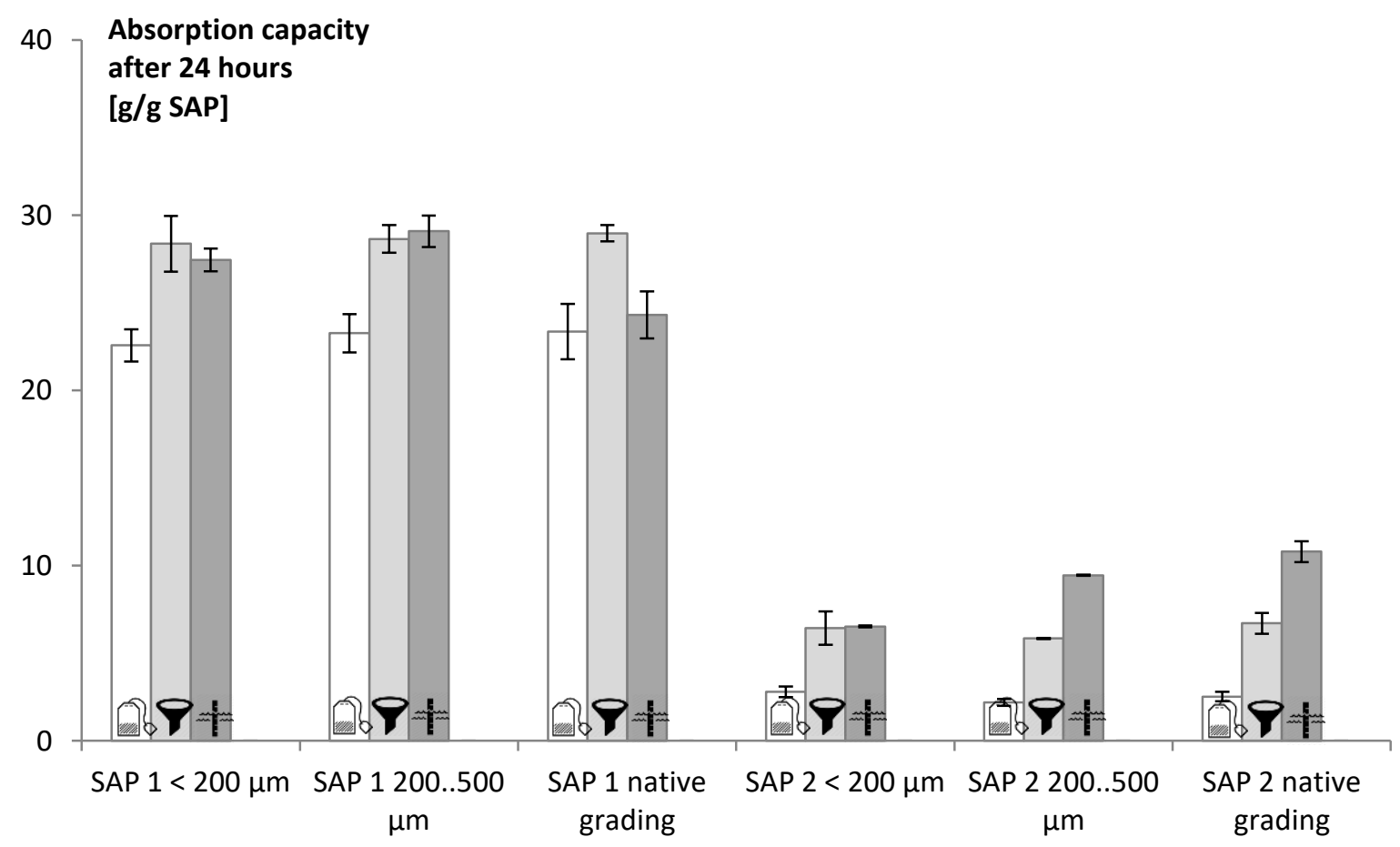

Figure 14: Comparison of the results obtained by participant 1 in the series with filtered 789 cement slurry of the shipped cement using different testing methods: tea-bag method, filtration method, rising water-head test and microscopic analysis. 


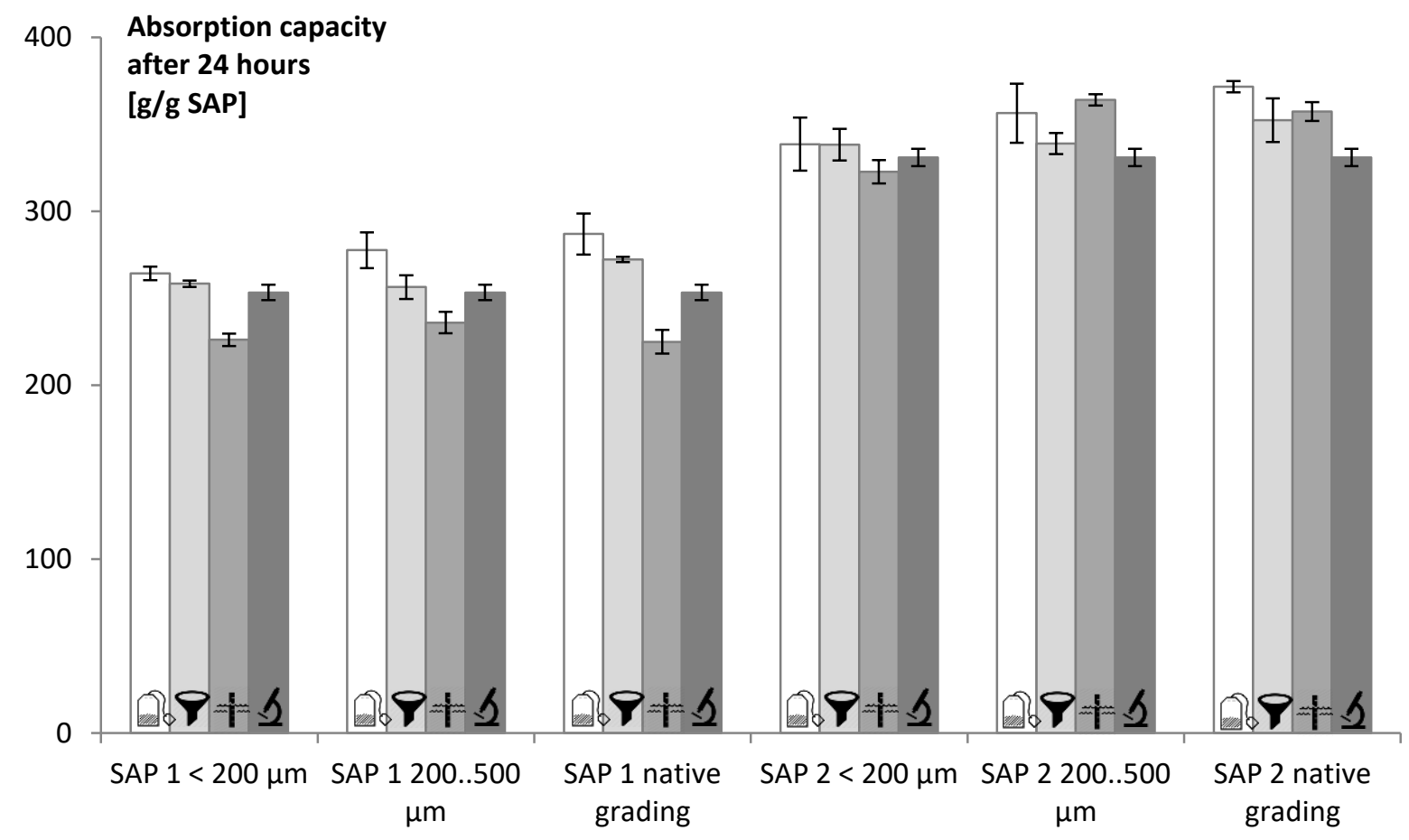

Figure 15: Comparison of the results obtained by participant 1 using different testing 795 methods in in the series with demineralized water using different testing 796 methods: tea-bag method, filtration method, rising water-head test and microscopic analysis. 
800

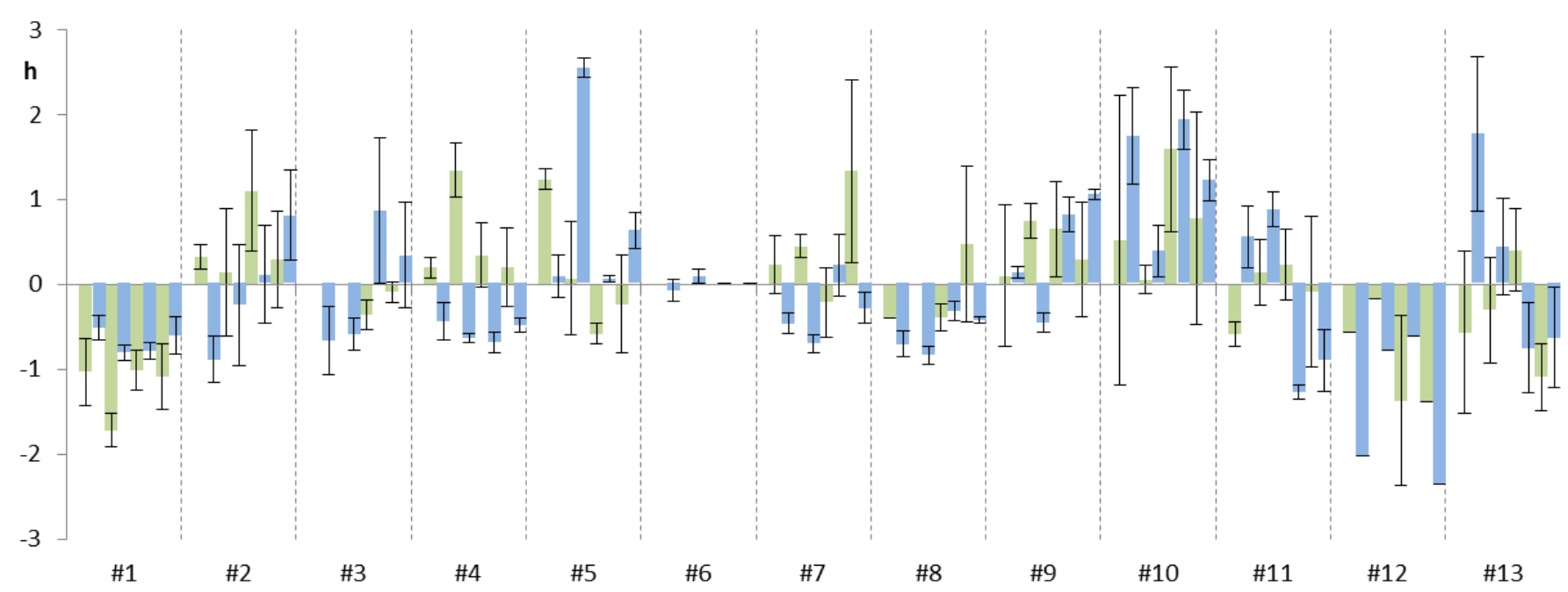

802

a)

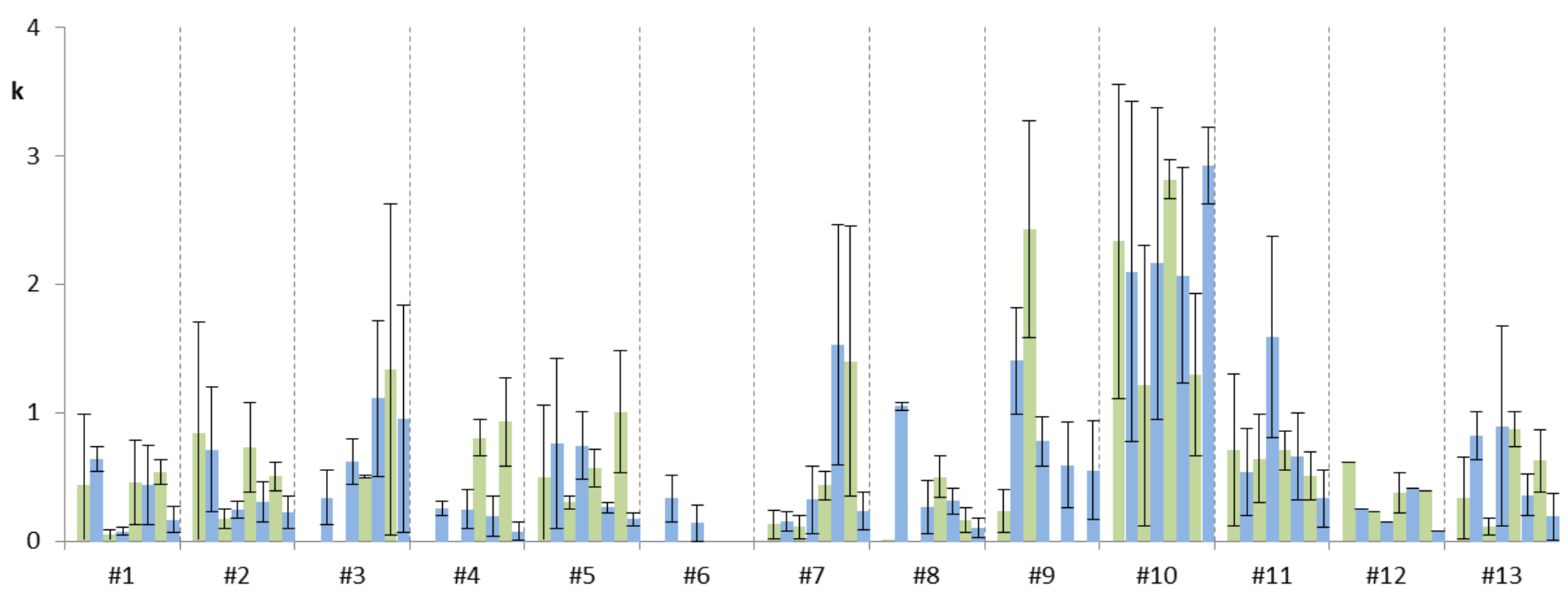

b)

803

805

806

Figure 16: Consistency statistics a) $\boldsymbol{h}$ and b) $\boldsymbol{k}$, showing the deviation from the overall average divided by the overall standard deviation and the participants standard deviation compared to the overall standard deviation of SAP 1 and SAP 2 in cement filtrate solution and demineralized water with the filtration method (green) and the tea-bag method (blue). No values shown means no tests performed and no standard deviation means no repetitive testing was performed. 